\title{
Transcriptomic profiling of Solanum peruvianum LA3858 revealed a Mi-3- mediated hypersensitive response to Meloidogyne incognita
}

Chong Du, Jingbin Jiang, He Zhang, Tingting Zhao, Huanhuan Yang, Dongye Zhang, Zhentong Zhao, Xiangyang Xu and Jingfu Li $i^{*}$

\begin{abstract}
Background: The Mi-1 gene was the first identified and cloned gene that provides resistance to root-knot nematodes (RKNs) in cultivated tomato. However, owing to its temperature sensitivity, this gene does not meet the need for breeding disease-resistant plants that grow under high temperature. In this study, Mi-3 was isolated from the wild species PI 126443 (LA3858) and was shown to display heat-stable resistance to RKNs. However, the mechanism that regulates this resistance remains unknown.

Results: In this study, 4760, 1024 and 137 differentially expressed genes (DEGs) were enriched on the basis of pairwise comparisons $\left(34^{\circ} \mathrm{C}\right.$ vs. $25^{\circ} \mathrm{C}$ ) at 0 (before inoculation), 3 and 6 days post-inoculation (dpi), respectively. A total of 7035 DEGs were identified from line LA3858 in the respective groups under the different soil temperature treatments. At 3 dpi, most DEGs were enriched in Kyoto Encyclopedia of Genes and Genomes (KEGG) pathways related to plant biotic responses, such as "plant-pathogen interaction" and "plant hormone signal transduction". Significantly enriched DEGs were found to encode key proteins such as R proteins and heat-shock proteins (HSPs). Moreover, other DEGs were found to participate in $\mathrm{Ca}^{2+}$ signal transduction; the production of ROS; DEGs encoding transcription factors (TFs) from the bHLH, TGA, ERF, heat-shock transcription factor (HSF) and WRKY families were highly expressed, which contribute to be involved into the formation of phytohormones, such as salicylic acid (SA), jasmonic acid (JA) and ethylene (ET), the expression of most was upregulated at $3 \mathrm{dpi}$ at the $25^{\circ} \mathrm{C}$ soil temperature compared with the $34^{\circ} \mathrm{C}$ soil temperature.

(Continued on next page)
\end{abstract}

\footnotetext{
*Correspondence: lijf_2005@126.com

Laboratory of Genetic Breeding in Tomato, College of Horticulture and Landscape Architecture, Northeast Agricultural University, Harbin 150030,

People's Republic of China
}

(c) The Author(s). 2020 Open Access This article is licensed under a Creative Commons Attribution 4.0 International License, which permits use, sharing, adaptation, distribution and reproduction in any medium or format, as long as you give appropriate credit to the original author(s) and the source, provide a link to the Creative Commons licence, and indicate if changes were made. The images or other third party material in this article are included in the article's Creative Commons licence, unless indicated otherwise in a credit line to the material. If material is not included in the article's Creative Commons licence and your intended use is not permitted by statutory regulation or exceeds the permitted use, you will need to obtain permission directly from the copyright holder. To view a copy of this licence, visit http://creativecommons.org/licenses/by/4.0/ The Creative Commons Public Domain Dedication waiver (http://creativecommons.org/publicdomain/zero/1.0/) applies to the data made available in this article, unless otherwise stated in a credit line to the data. 


\begin{abstract}
(Continued from previous page)
Conclusion: Taken together, the results of our study revealed reliable candidate genes from wild materials LA3858, that are related to Mi-3-mediate resistance to Meloidogyne incognita. A large number of vital pathways and DEGs were expressed specifically in accession LA3858 grown at $34^{\circ} \mathrm{C}$ and $25^{\circ} \mathrm{C}$ soil temperatures at 3 dpi. Upon infection by RKNs, pattern-recognition receptors (PRRs) specifically recognized conserved pathogen-associated molecular patterns (PAMPs) as a result of pathogen-triggered immunity (PTI), and the downstream defensive signal transduction pathway was likely activated through $\mathrm{Ca}^{2+}$ signal channels. The expression of various TFs was induced to synthesize phytohormones and activate $\mathrm{R}$ proteins related to resistance, resulting in the development of effectortriggered immunity (ETI). Last, a hypersensitive response in the roots occurred, which was probably induced by the accumulation of ROS.
\end{abstract}

Keywords: RNA sequencing, Root-knot nematode, Mi-3, ROS, Soil temperature

\section{Background}

Members of the genus Meloidogyne, which represent major pests worldwide, have a substantial negative influence on the development of various plant species [1]. The J2 stage (the second stage of juveniles) is the main infection stage of RKNs; during this stage, giant cells (GCs) form in the roots of plants and absorb nutrients from the roots for their own growth and reproduction [2]. Once established, J2-stage RKNs undergo three successive molts to become adult females [3]. The development of genetic resistance is an effective method for reducing yield losses caused by RKN infection.

ROS have a substantial influence on reactions to biotic and abiotic stresses. Phytohormones such as JA and SA not only function to regulate plant growth but also are involved in plant defense signaling pathways [4]. Genes that encode nucleotide-binding site-leucine-rich repeats (NBSLRRs) are the predominant members of the $R$ gene family, accounting for approximately $80 \%$ of the more than 140 cloned $R$ genes [5]. In potato, Gpa2 is an $R$ gene that encodes the GPA2 protein, which depends on the recognition specificity afforded by both amino acid 187 and the Gpa2 LRR domain and provides resistance against two Globodera pallida nematode populations (D383 and D372) [6]. Additionally, the $R h g 1$ gene from soybean, the $M e 3$ and $\mathrm{Me} 4$ genes from pepper, and the $\mathrm{Mi}-1$ gene from tomato provide resistance against specific strains of nematodes.

The $M i-1$ gene, which has been mapped to the short arm of chromosome 6 and whose product contains a putative coiled-coil domain preceding the nucleotidebinding site (NBS) [7], is the major effective $R$ gene against RKN species in tomato (Solanum lycopersicum) [8]. The $M i$ genomic region contains three homologous genes, which are referred to as $\mathrm{Mi}-1.1, \mathrm{Mi}-1.2$ and $\mathrm{Mi}$ 1.3. Of these genes, only $M i-1.2$ provides resistance against RKNs, including Meloidogyne incognita, Meloidogyne javanica and Meloidogyne arenaria [9]. Mi-1 is an effective genetic resource for use against RKNs; however, $\mathrm{Mi}$-1-mediated resistance is inactive at soil temperatures greater than $28^{\circ} \mathrm{C}$ [10]. Thus, additional heat-stable genes that provide resistance against RKNs must be identified to overcome this barrier. Recently, Mi-3 has attracted increased attention because of its heat-stable characteristics. In Solanum peruvianum LA3858, Mi-3 is located on the short arm of chromosome 12 and contains a $600-\mathrm{kb}$ contig between the $\mathrm{Mi}$-3-flanking markers TG180 and NR18, corresponding to a genetic distance of approximately $7.2 \mathrm{cM}$ [11]. Although it originates from a wild species, $\mathrm{Mi}$-3, whose product functions effectively when temperatures reach $32{ }^{\circ} \mathrm{C}$, could be a valuable source of resistance for cultivated tomato. However, self-incompatibility and distant hybridization incompatibility are the primary barriers preventing this gene from being finely mapped and cloned [12].

This study was designed to investigate via RNA sequencing (RNA-seq) $\mathrm{Mi}$-3-mediated resistance in plants grown at two different soil temperatures $\left(34^{\circ} \mathrm{C}\right.$ and $\left.25^{\circ} \mathrm{C}\right)$ following inoculation with $M$. incognita. Our goal was to identify key DEGs at the transcriptional level from the perspectives of PTI and ETI. We analyzed the plant defense response pathways with which these DEGs were significantly involved. Last, the Mi-3 gene-mediated disease response was characterized via a functional analysis of the proteins encoded by the DEGs in combination with analyses of the differences in DEG expression trends between the resistant $\left(25^{\circ} \mathrm{C}\right)$ and susceptible $\left(34^{\circ} \mathrm{C}\right)$ lines.

\section{Results}

\section{RKN disease evaluation under different temperature} treatments

According to the infection results, the Moneymaker line displayed relatively consistent susceptibility to $M$. incognita at both soil temperatures (Fig. 1a). According to the resistance index results, all the seedlings were rated as $\mathrm{S}$ and HS (Additional file 1). In accession LA3858, all 8 plants at the soil temperature of $25^{\circ} \mathrm{C}$ were immune to infection (rated as HR). At the soil temperature of $32^{\circ} \mathrm{C}$, very small galls had developed on the roots; however, all plants were rated as HR. When the plants were subjected to a soil temperature of $34{ }^{\circ} \mathrm{C}$, gall formation on 


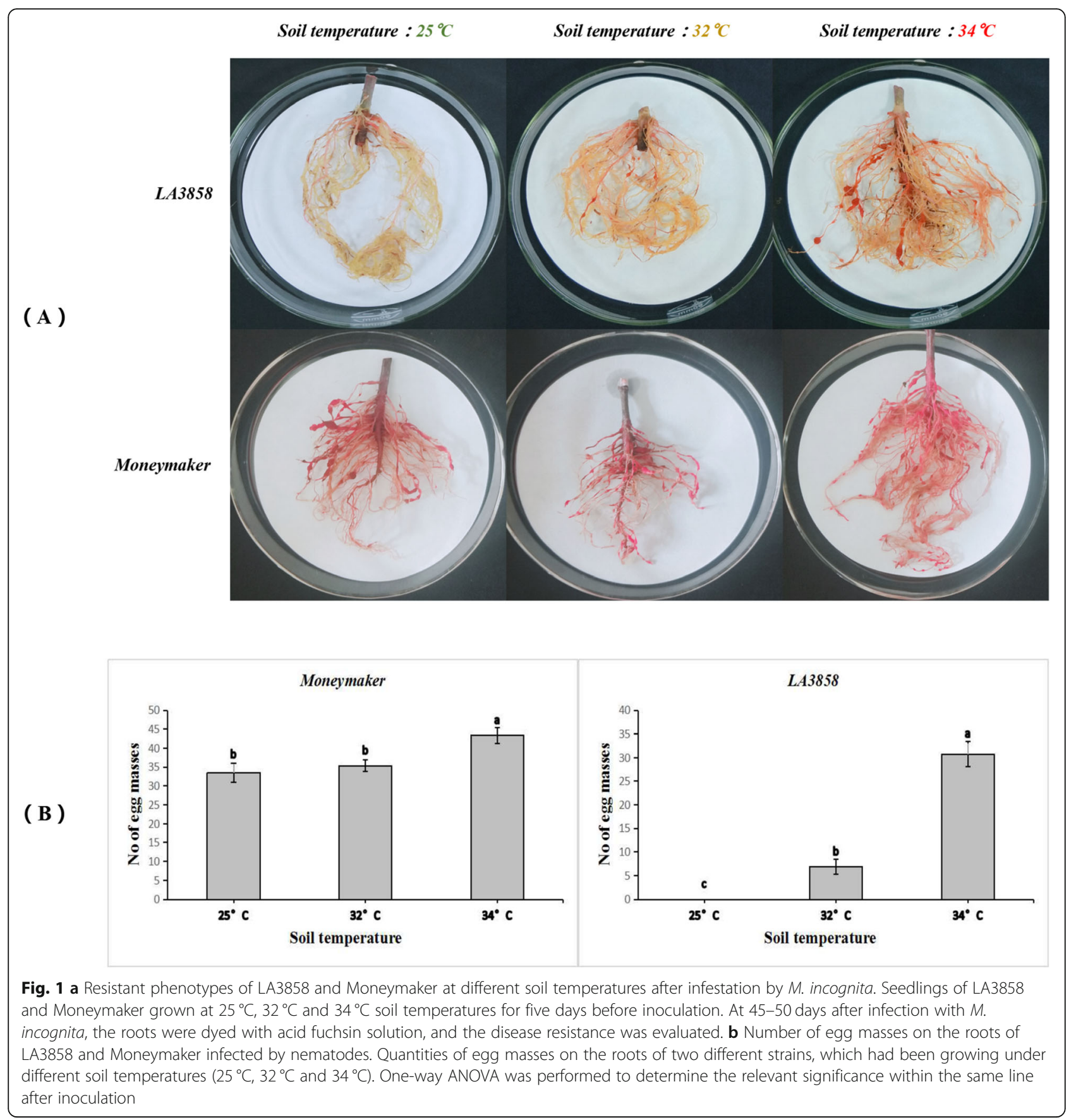

the roots was enhanced, and the resistance was rated as $\mathrm{S}$ and HS. According to a one-way ANOVA, although the number of egg masses from the Moneymaker line was not significant $(P>0.05)$, the root gall numbers on accession LA3858 plants in the $34{ }^{\circ} \mathrm{C}$ soil temperature treatment were obviously greater than those on plants in the other two soil treatments $(P \leq 0.05)$, which indicated that any resistance to RKNs of LA3858 will be completely absent (HS) at $34^{\circ} \mathrm{C}$ (Fig. 1b).

\section{Illumina sequencing and alignment to the reference genome}

RNA-seq data were generated from 18 samples of the wild species LA3858 at different stages following inoculation (0, 3 and $6 \mathrm{dpi}$ ). After sequencing a total of 89 billion fragments of clean reads, we obtained approximately $49 \mathrm{M}$ reads for each sample after aligning them to the reference genome (SL 3.0, ftp://ftp.sgn.cornell.edu/genomes/Solanum_lycopersicum/assembly/build_3.00/2 via TopHat2 (version 2.0.3.12). 
Approximately $46 \mathrm{M}$ clean reads per sample were obtained for subsequent analysis after the rRNA sequences, adapter sequences and low-quality reads were filtered and removed. The Q20 values (base calling error probability $=99 \%$ ) of the 18 samples were greater than $98 \%$. The expression profiles of 35,768 genes were ultimately used for further analysis (Fig. 2).

\section{DEGs observed at $25^{\circ} \mathrm{C}$ and $34^{\circ} \mathrm{C}$ soil temperatures}

The DEG analysis revealed that 5921 DEGs were enriched $(P \leq 0.05)$ in the three groups; the expression of 2802, 904 and 100 of these genes was upregulated, and that of 1958, 120 and 37 DEGs was downregulated in $34^{\circ} \mathrm{C}$ vs. $25^{\circ} \mathrm{C}$ at 0 (before inoculation), 3 and $6 \mathrm{dpi}$ (HS0 vs. HR0, HS3 vs. HR3 and HS6 vs. HR6), respectively (Fig. 3). The overlapping genes among these groups are shown in Fig. 4.

GO enrichment analysis revealed the enrichment of the DEGs with respect to the following three categories: cellular component, molecular function and biological process. Most of the DEGs were enriched $(P \leq 0.05)$ in the cellular component category and were involved in the "cell", "cell part", "membrane", and "organelle" terms. The significantly enriched terms $(P \leq 0.05)$ in the molecular function category were "binding", "catalytic activity" and "transporter activity", and the enriched terms

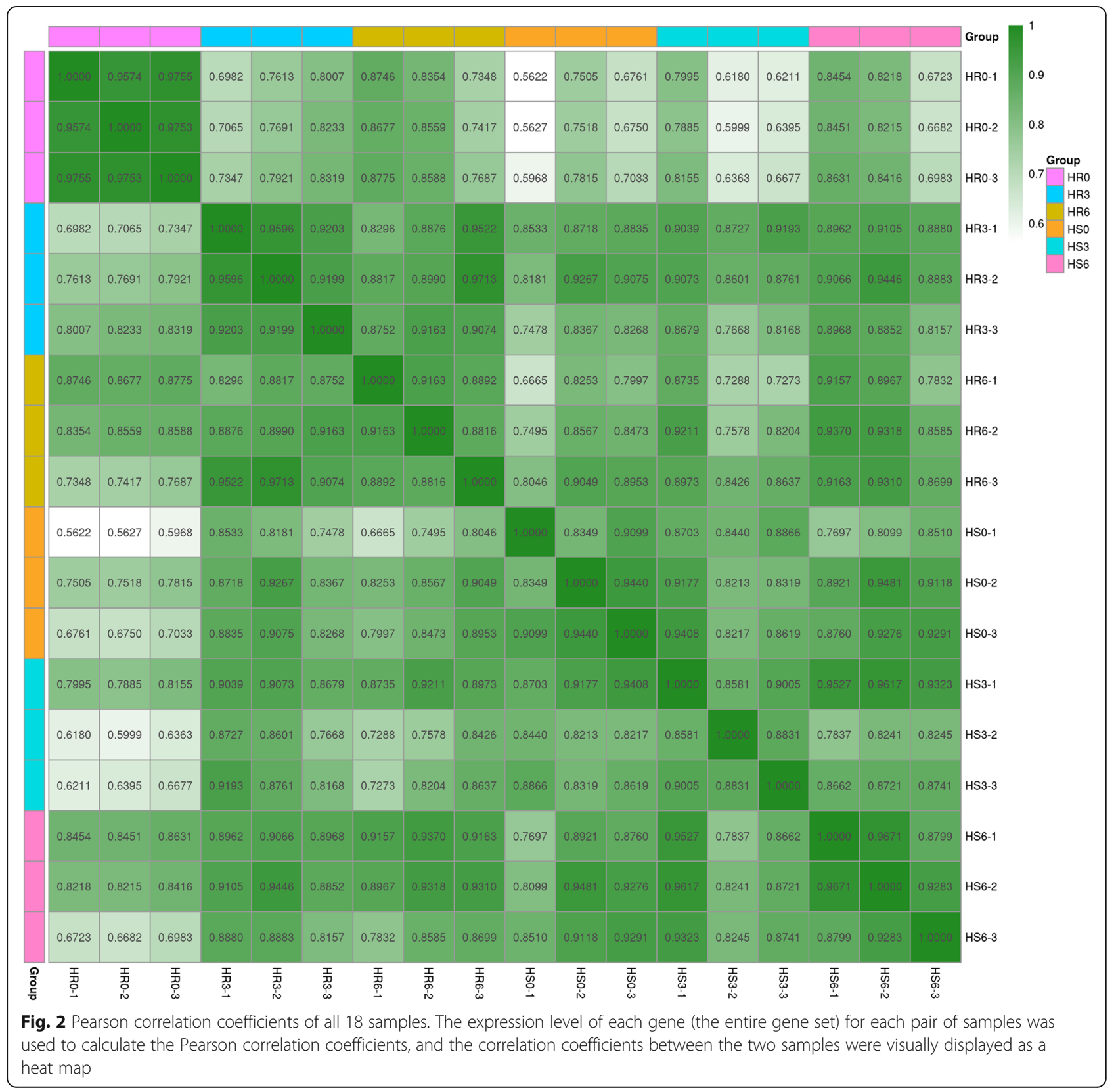




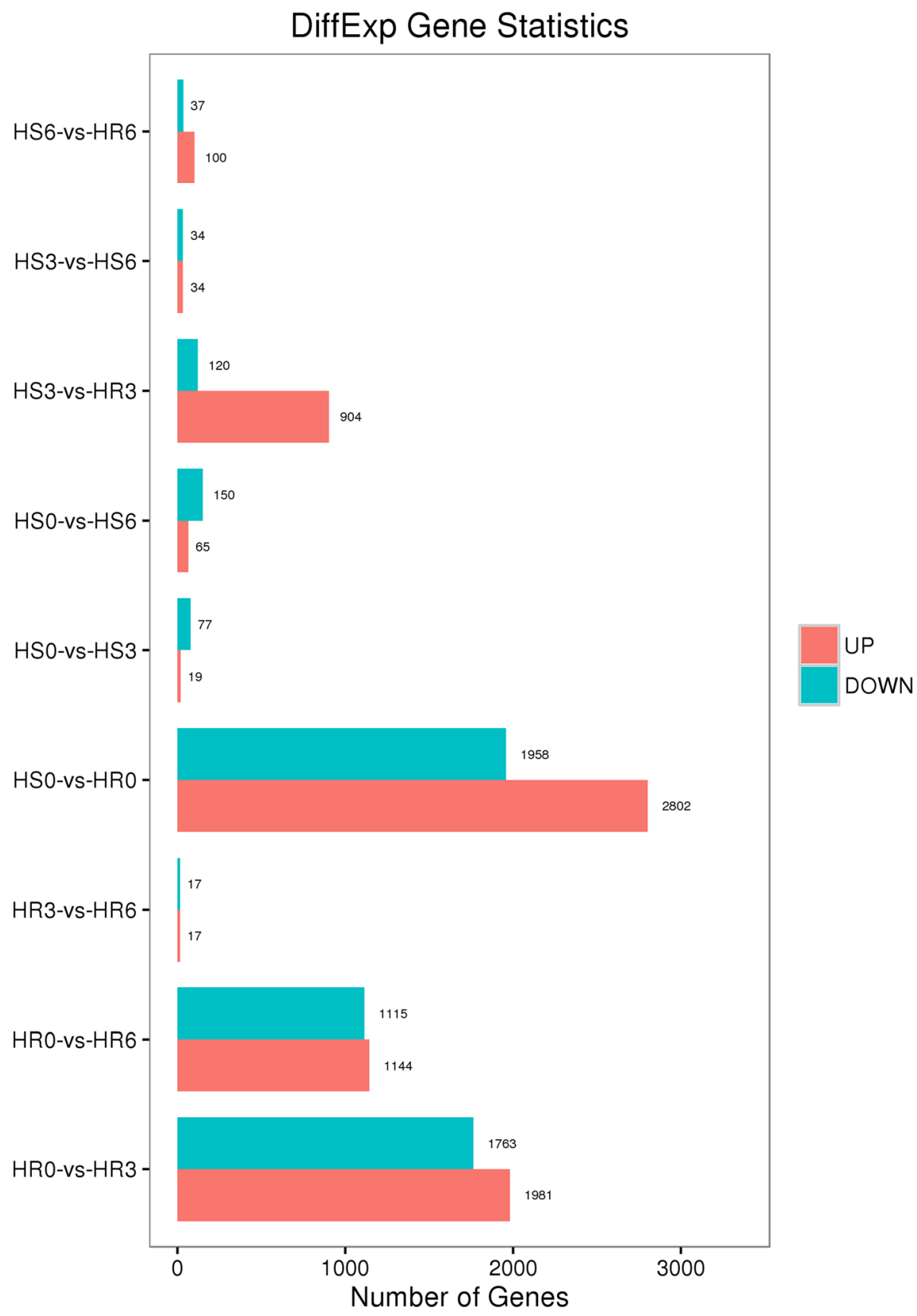

Fig. 3 Statistics of the DEGs among different comparison groups. The FDR and log2FC were used to screen for DEGs with an FDR $<0.05$ and a $|\log 2 \mathrm{FC}|>1$

$(P \leq 0.05)$ in the biological process category included "biological regulation", "cellular process", "metabolic process", and "response to stimulus and signaling", which were related to disease resistance [13] (Figure S1). Notably, in the HS3 vs. HR3 comparison, many key KEGG pathways related to biotic stress were significantly enriched $(P \leq 0.05)$, including "plant-pathogen interaction" (16 DEGs), "plant hormone signal transduction" (16 DEGs), and "brassinosteroid biosynthesis" (3) (Fig. 5).
However, in the HS0 vs. HR0 and HS6 vs. HR6 comparisons, enrichment of these key pathways was not obvious.

Trends of DEGs in the same lines $\left(25^{\circ} \mathrm{C}\right.$ and $\left.34^{\circ} \mathrm{C}\right)$

To analyze the DEGs in the same lines at different time points (0, 3 and $6 \mathrm{dpi}$ ), trend analysis was used to discover DEG expression patterns. When LA3858 was subjected to the $25^{\circ} \mathrm{C}$ soil temperature treatment, most DEGs were enriched in profiles 1 and $6(P \leq 0.05)$ 


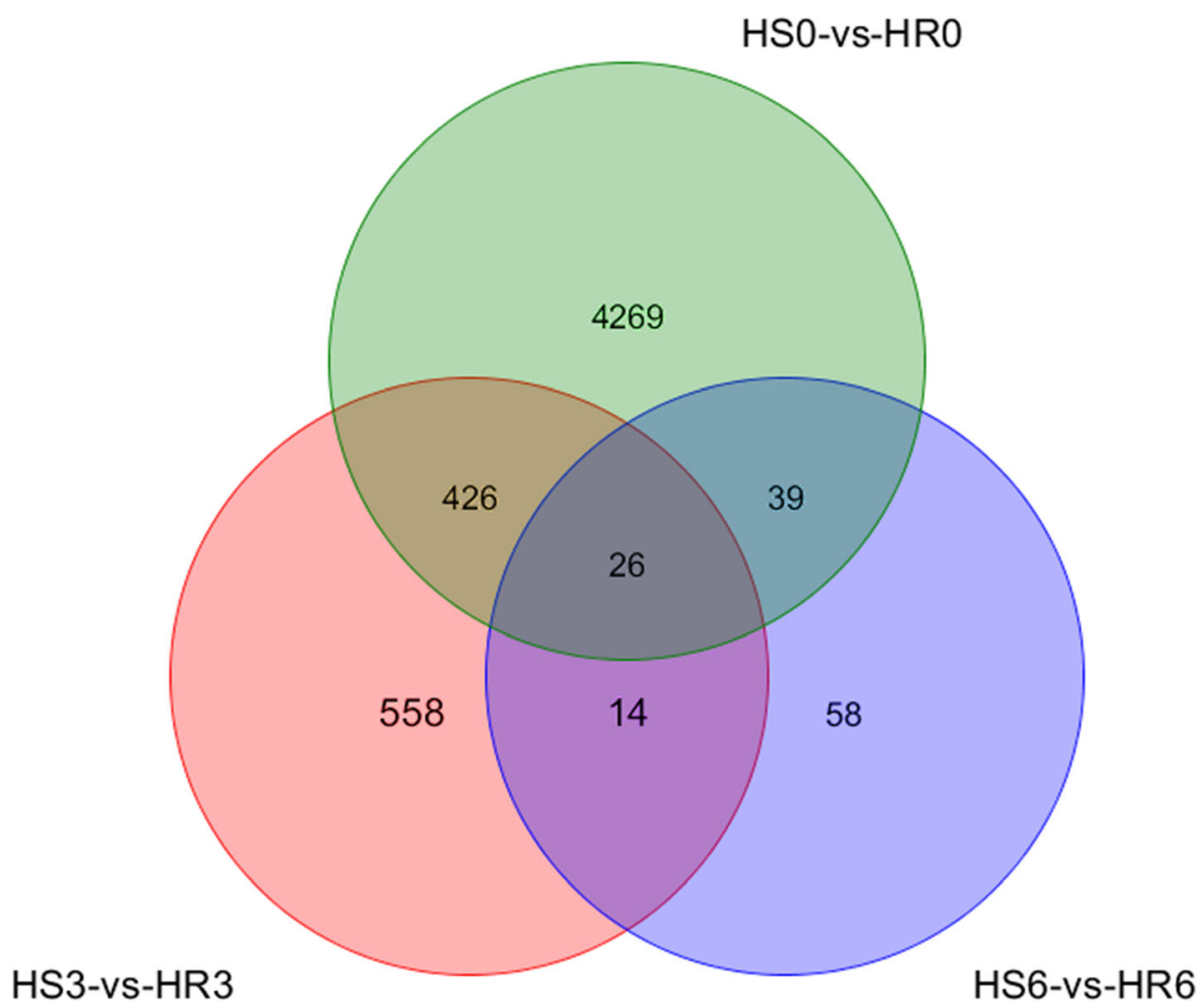

Fig. 4 Venn diagram of the different groups of DEGs. The overlaps of DEGs from the pairwise comparisons of three groups (A - HSO vs. HRO, B HS3 vs. HR3, and C - HS6 vs. HR6). The DEGs were chosen at 0, 3 and 6 dpi as time points for analysis

(Fig. 6a). The KEGG analysis revealed a unique increasing expression trend (Fig. 6b), as profile 6 exhibited a high enrichment of DEGs. Several key pathways related to disease resistance were also significantly enriched, such as "plant hormone signal transduction" (31 DEGs) and "plant-pathogen interaction" (25 DEGs) (Fig. 6c). In $34{ }^{\circ} \mathrm{C}$ line, most DEGs were significantly enriched in profiles 2 and $4(P \leq 0.05)$ (Fig. 7a). Similarly, because DEGs enriched in profile 2 exhibited a specific downregulation expression trend (Fig. 7b), profile 2 received increased attention. In addition to the "plant-pathogen interaction" (9 DEGs) pathway, the "phenylpropanoid biosynthesis" (15 DEGs) and "flavonoid biosynthesis" (4 DEGs) pathways, whose metabolites often play an active role in regulating the response to biotic stimulus, were also enriched in profile 2 (Fig. $7 \mathrm{c}$ ).

\section{Gene expression under different temperature treatments at $3 \mathrm{dpi}$}

At the important time period of $3 \mathrm{dpi}$, in terms of the key pathways, "plant-pathogen interaction" and "plant hormone signal transduction" were the primary ones identified.

In the "plant-pathogen interaction" pathway, the expression levels of 2 genes that encode calciumdependent protein kinases (CDPKs), 3 genes that encode respiratory burst oxidases (RBOHs), and 3 genes that encode LRR receptor-like serine/threonine-protein kinases (FLS2s) were upregulated. Additionally, the expression levels of 2 genes that encode disease resistance proteins (RPs; RPM1 and PRS2) and 2 genes that encode HSPs (HSP90s) were also upregulated in the plants grown at $25^{\circ} \mathrm{C}$ soil temperature. The other genes encode enhanced disease susceptibility 1 protein (EDS1), which is involved in programmed cell death (PCD), and WRKY TFs. In the "plant hormone signal transduction" pathway, 16 genes were enriched significantly $(P \leq 0.05)$, with 11 involved in the auxin response, including those encoding auxin-responsive proteins (IAAs), auxin response factors (ARFs), auxin-responsive GH3 family members and SAUR proteins; the expression of 10 of these genes was upregulated. Other genes encode a serine/threonine-protein kinase (SRK2), which is involved in the abscisic acid pathway, a brassinosteroid (BR) signaling kinase (BSK), which is involved in BR biosynthesis, and 2 TGA TFs, which are involved with SA (Table 1).

The trend analysis revealed that, in $25^{\circ} \mathrm{C}$ line, DEGs were enriched significantly $(P \leq 0.05)$ in profile 6 class. In the "plant-pathogen interaction" pathway; in addition to the above mentioned protein-coding genes, the genes encoding RPM1-interacting protein (RIN4) and pathogen-induced protein kinase (PIK1) were highly 


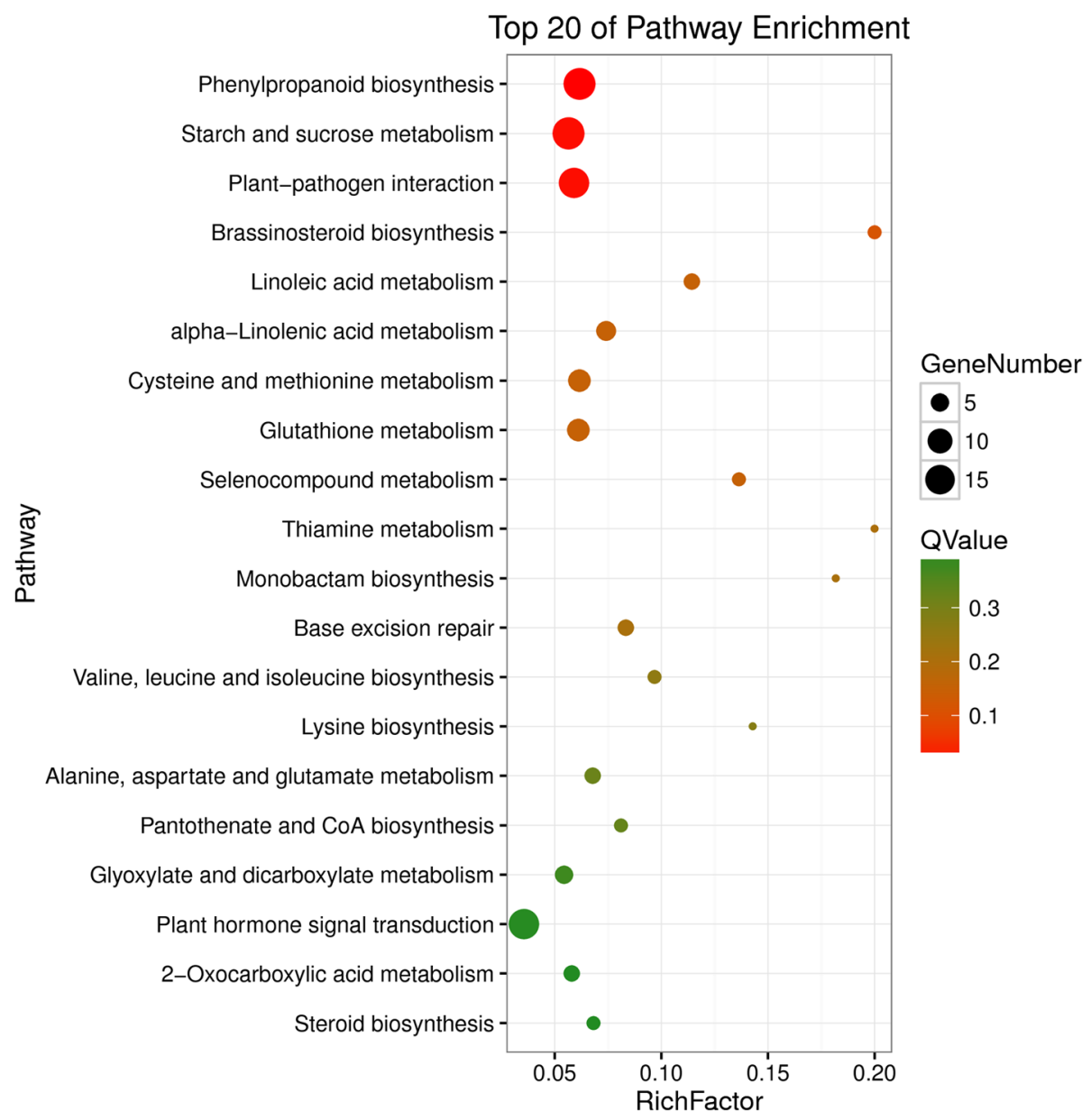

Fig. 5 KEGG pathway analysis of pairwise comparisons (HS3 vs. HR3) at 3 dpi. KEGG pathways analysis for $\mathrm{HS} 3$ vs. $\mathrm{HR} 3\left(34^{\circ} \mathrm{C}\right.$ vs. $25^{\circ} \mathrm{C}-3$ dpi). The chart shows the top 20 pathways enriched in the selected group. The plot contains Q-values $(<0.05)$ shown from the smallest to the largest for the 20 pathways. The values range from 0 to 1 , and the closer to 0 the value is, the more significant the enrichment

enriched. Compared with the $34^{\circ} \mathrm{C}$ vs. $25^{\circ} \mathrm{C}$, a large number of genes were involved in other key processes, such as those associated with cytokinin (CK), gibberellin (GA), ET and JA in the "plant hormone signal transduction" pathway (Table 2). In $34^{\circ} \mathrm{C}$ line, DEGs in profile 2 were highly enriched $(P \leq 0.05)$. The expression levels of 9 DEGs that encoded FLS2, RBOH, RPS2, HSP90 and WRKY, which involved into pathway "plant-pathogen interaction", decreased at $3 \mathrm{dpi}$ (Table 3).

\section{Analysis of the hub genes from the coexpression network during incompatible interactions}

The genes related to the regulation of the resistance mechanism of LA3858 at different soil temperatures were further investigated. After clustering the module genes according to the standards mentioned above, we selected a total of 17,184 genes for the construction of a scale-free coexpression network. Thirteen coexpression modules were constructed (Fig. 8). Of these modules, a total of 6 (i.e., bisque4, brown, darkmagenta, darkorange, darkorange 2 and pink) were selected because of the specificity of the expression pattern at each time period. Among these 6 modules, which had been subjected to KEGG analysis, the darkorange and pink modules attracted our attention because the expression of the DEGs in both modules tended increase at 3 dpi (Fig. 9), and the "plant-pathogen interaction" pathway was also significantly enriched $(P \leq 0.05)$ in both modules (Figure S2). With respect to genes, Pearson correlation coefficients $\geq 0.8$ were filtered to establish DEGs coexpression network to reveal hub genes whose expression is induced during Mi-3-mediated resistance (Fig. 10). In the darkorange module, 6 hub genes encode histidine decarboxylase (HDC), 3 genes encode calcium-binding protein (CML) and one encodes an ET-responsive transcription factor (ERF). In the pink module, CDPK and $\mathrm{RBOH}$ were also found to be encoded by hub genes. These results suggested that $\mathrm{Ca}^{2+}$ channels may play a 

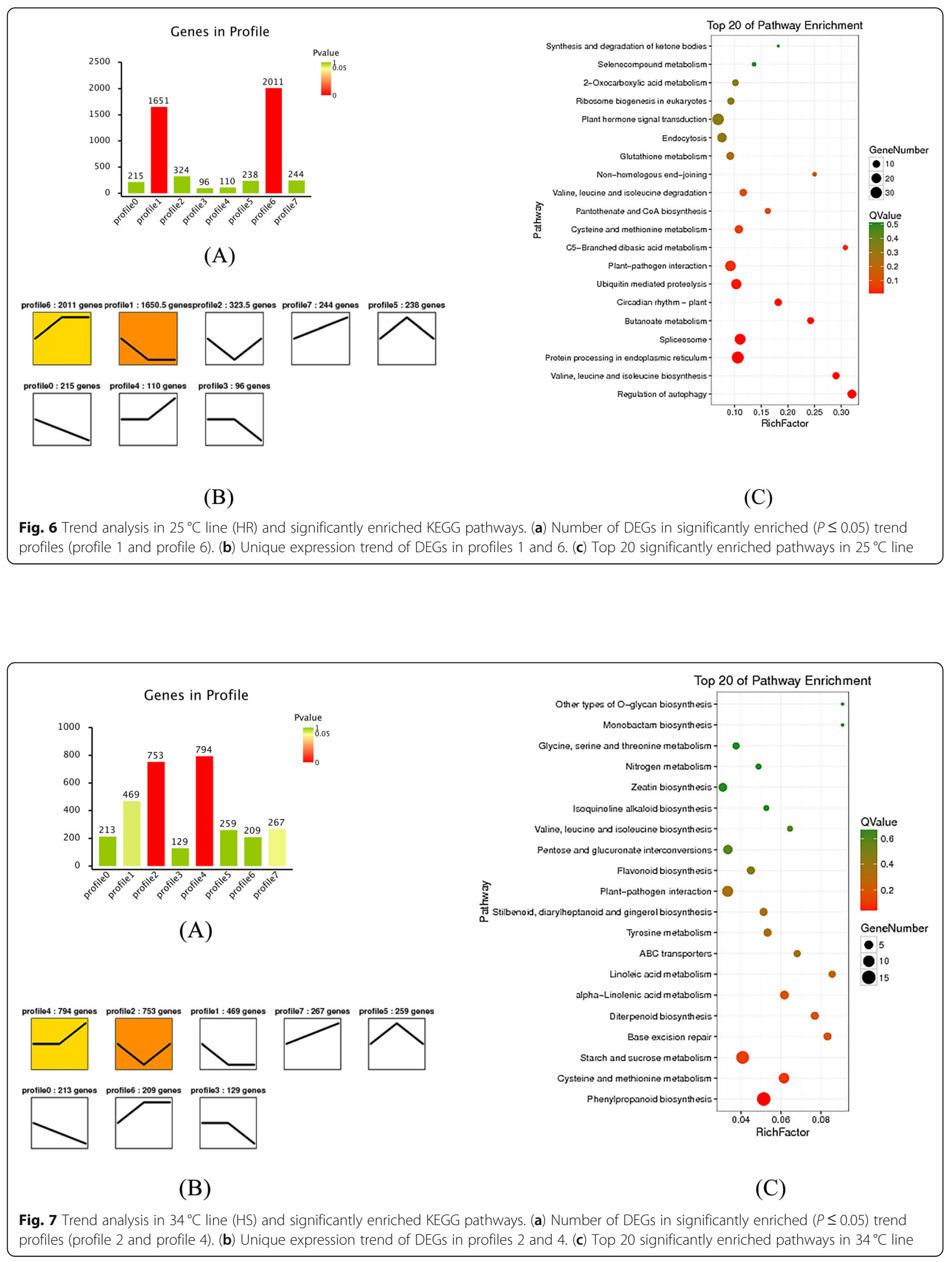
Table 1 Key DEGs that are involved in the resistance response to infection by RKNs and are enriched in the $34^{\circ} \mathrm{C}$ vs. $25^{\circ} \mathrm{C}$ at 3 dpi

\begin{tabular}{|c|c|c|c|}
\hline Gene ID & Symbol & Log2(fold change)-HS3 vs. HR3 & Pathway \\
\hline Solyc01g106620.2 & PR1 & -2.32 & Plant-pathogen interaction/Plant hormone signal transduction \\
\hline Solyc02g072480.3 & GSO1(FLS2) & 2.48 & Plant-pathogen interaction \\
\hline Solyc03g033540.3 & CPK16(CDPK) & 1.19 & Plant-pathogen interaction \\
\hline Solyc03g044900.3 & CML41 & 2.11 & Plant-pathogen interaction \\
\hline Solyc04g007090.1 & $\mathrm{R} 1 \mathrm{~A}(\mathrm{RPM} 1)$ & 9.06 & Plant-pathogen interaction \\
\hline Solyc04g014650.3 & At3g47570(FLS2) & 2.43 & Plant-pathogen interaction \\
\hline Solyc05g010670.3 & Hsp83(HSP90) & 1.21 & Plant-pathogen interaction \\
\hline Solyc06g006020.2 & FLS2 & 1.4 & Plant-pathogen interaction \\
\hline Solyc06g036290.3 & HSP83A(HSP90) & 1.42 & Plant-pathogen interaction \\
\hline Solyc06g068680.3 & $\mathrm{RBOHD}$ & 1.94 & Plant-pathogen interaction \\
\hline Solyc06g071280.3 & EDS1 & 1.36 & Plant-pathogen interaction \\
\hline Solyc07g042460.2 & RBOHE & 1.66 & Plant-pathogen interaction \\
\hline Solyc08g007250.2 & At4g27190(RPS2) & 2.3 & Plant-pathogen interaction \\
\hline Solyc08g081690.3 & $\mathrm{RBOHA}$ & 1.42 & Plant-pathogen interaction \\
\hline Solyc12g005040.2 & CPK2(CDPK) & 1.53 & Plant-pathogen interaction \\
\hline Solyc12g006170.2 & WRKY20 & 1.37 & Plant-pathogen interaction \\
\hline Solyc01g096070.3 & ARF9 & 1.62 & Plant hormone signal transduction \\
\hline Solyc01g097290.3 & IAA16 & 1.91 & Plant hormone signal transduction \\
\hline Solyc02g092820.3 & $\mathrm{GH} 3.1$ & -3.1 & Plant hormone signal transduction \\
\hline Solyc04g081250.1 & SAUR40 & 10.1 & Plant hormone signal transduction \\
\hline Solyc05g056550.3 & SAPK7 & 1.21 & Plant hormone signal transduction \\
\hline Solyc06g008580.3 & IAA3 & 3.04 & Plant hormone signal transduction \\
\hline Solyc06g074320.3 & TGA21 & 1.2 & Plant hormone signal transduction \\
\hline Solyc06g084070.3 & $A \cup \times 22 D$ & 1.71 & Plant hormone signal transduction \\
\hline Solyc07g063850.3 & GH3.6 & 1.89 & Plant hormone signal transduction \\
\hline Solyc08g008380.3 & ARF9 & 1.85 & Plant hormone signal transduction \\
\hline Solyc08g082630.3 & ARF9 & 1.87 & Plant hormone signal transduction \\
\hline Solyc09g083280.3 & IAA4/5 & 1.62 & Plant hormone signal transduction \\
\hline Solyc1 1g068370.2 & TGA2.3 & 1.6 & Plant hormone signal transduction \\
\hline Solyc12g096980.2 & IAA13 & 2.67 & Plant hormone signal transduction \\
\hline Solyc12g099830.2 & At5g41260(BSK) & 1.33 & Plant hormone signal transduction \\
\hline
\end{tabular}

key role in signal transduction during nematode infection [14], at the same time, the level of ROS may also contribute to the regulation of resistance, which is consistent with our previous results obtained from incompatible interactions [15] (Additional file 2).

\section{Key TFs that function during infection in Mi-3-mediated resistance}

RNA-seq analysis revealed a total of 832 TFs. Five main TF categories related to disease resistance in plants were identified: WRKYs, heat-shock transcription factors (HSFs), bHLHs, TGAs, and ERFs [16]. On the basis of the significant expression levels $(P \leq 0.05)$, we compared the detailed expression trends of the DEGs that encode
TFs from the above 5 families between $34^{\circ} \mathrm{C}$ and $25^{\circ} \mathrm{C}$ (Additional file 3). There were more enriched DEGs that encode TFs from these families at 0 days (before inoculation) than at the other two stages ( $3 \mathrm{dpi}$ and $6 \mathrm{dpi})$. This was most likely due to the increase in soil temperature, and the DEGs that encode TFs involved in the response to abiotic stress were significantly enriched. At $3 \mathrm{dpi}$, the expression of nearly all the significantly enriched DEGs of the TFs was upregulated, and among those that encode TFs, the number of DEGs encoding WRKY TFs was the largest. Almost no DEGs encoding TFs were enriched at $6 \mathrm{dpi}$, which indicated again that $\mathrm{Mi}$-3-mediated resistance occurs mainly during the early stages of nematode infection (Fig. 11). 
Table 2 Key DEGs that are involved in the resistance response to infection by RKNs and are enriched according to the trend analysis of $25^{\circ} \mathrm{C}$ line (growing at a soil temperature of $25^{\circ} \mathrm{C}$ )

\begin{tabular}{|c|c|c|c|c|c|c|}
\hline Gene ID & Symbol & CK-log2 (1) & $\log 2(\mathrm{HRO}$ vs. HR3) & $\log 2(\mathrm{HRO}$ vs. HR6) & Profile & Pathway \\
\hline Solyc01g108190.3 & CML1 & 0 & 1.85 & 1.38 & 6 & Plant-pathogen interaction \\
\hline Solyc02g037540.2 & At4g27220(RPS2) & 0 & 1.36 & 1.44 & 6 & Plant-pathogen interaction \\
\hline Solyc02g081040.3 & CERK1 & 0 & 1.12 & 1.2 & 6 & Plant-pathogen interaction \\
\hline Solyc02g083850.3 & CPK16(CDPK) & 0 & 1.38 & 1.58 & 6 & Plant-pathogen interaction \\
\hline Solyc02g090810.3 & $/(\mathrm{CML})$ & 0 & 1.22 & 0.69 & 6 & Plant-pathogen interaction \\
\hline Solyc03g005660.3 & $\mathrm{R} 1 \mathrm{~A}(\mathrm{RPM} 1)$ & 0 & 0.9 & 1.21 & 6 & Plant-pathogen interaction \\
\hline Solyc03g007250.1 & CNGC1 & 0 & 1 & 0.7 & 6 & Plant-pathogen interaction \\
\hline Solyc03g007260.3 & CNGC1 & 0 & 1.05 & 0.9 & 6 & Plant-pathogen interaction \\
\hline Solyc03g007890.3 & HSP83A(HSP90) & 0 & 4.12 & 4.11 & 6 & Plant-pathogen interaction \\
\hline Solyc03g026340.3 & CPK26(CDPK) & 0 & 1.22 & 1.08 & 6 & Plant-pathogen interaction \\
\hline Solyc03g033540.3 & CPK16(CDPK) & 0 & 1.24 & 1.29 & 6 & Plant-pathogen interaction \\
\hline Solyc03g044900.3 & CML41 & 0 & 1.5 & 0.83 & 6 & Plant-pathogen interaction \\
\hline Solyc03g098210.3 & CNGC20 & 0 & 1.36 & 1.57 & 6 & Plant-pathogen interaction \\
\hline Solyc04g007090.1 & $\mathrm{R} 1 \mathrm{~A}(\mathrm{RPM} 1)$ & 0 & 1.37 & 1.44 & 6 & Plant-pathogen interaction \\
\hline Solyc04g081910.3 & CPK29(CDPK) & 0 & 1.04 & 0.65 & 6 & Plant-pathogen interaction \\
\hline Solyc06g006020.2 & FLS2 & 0 & 1.18 & 1.55 & 6 & Plant-pathogen interaction \\
\hline Solyc06g036290.3 & HSP83A(HSP90) & 0 & 5.44 & 5.18 & 6 & Plant-pathogen interaction \\
\hline Solyc06g068680.3 & $\mathrm{RBOHD}$ & 0 & 1.21 & 0.8 & 6 & Plant-pathogen interaction \\
\hline Solyc06g075550.3 & CDL1-like (PIK1) & 0 & 1.94 & 2.52 & 6 & Plant-pathogen interaction \\
\hline Solyc07g047960.3 & WRKY1 & 0 & 1.41 & 1.52 & 6 & Plant-pathogen interaction \\
\hline Solyc07g065840.2 & HSC80(HSP90) & 0 & 1.58 & 1.24 & 6 & Plant-pathogen interaction \\
\hline Solyc08g076493.1 & CML17 & 0 & 1.01 & 0.71 & 6 & Plant-pathogen interaction \\
\hline Solyc09g007020.1 & PR1 & 0 & 4.03 & 4.83 & 6 & Plant-pathogen interaction \\
\hline Solyc09g059430.3 & RIN4 & 0 & 0.83 & 1.09 & 6 & Plant-pathogen interaction \\
\hline Solyc12g006170.2 & WRKY20 & 0 & 1.37 & 1.24 & 6 & Plant-pathogen interaction \\
\hline Solyc01g008980.3 & DPBF4(ABF) & 0 & 1.48 & 1.25 & 6 & Plant hormone signal transduction \\
\hline Solyc01g095700.3 & PYL8 & 0 & 1.74 & 1.42 & 6 & Plant hormone signal transduction \\
\hline Solyc01g096810.3 & EIN3 & 0 & 1.03 & 0.81 & 6 & Plant hormone signal transduction \\
\hline Solyc01g098400.3 & AHP1 & 0 & 0.88 & 1.04 & 6 & Plant hormone signal transduction \\
\hline Solyc01g102300.3 & PIF3 & 0 & 1.03 & 0.62 & 6 & Plant hormone signal transduction \\
\hline Solyc01g104650.3 & GBF4(ABF) & 0 & 2.7 & 2.32 & 6 & Plant hormone signal transduction \\
\hline Solyc01g107400.2 & $\mathrm{GH} 3.1$ & 0 & 1.46 & 1.02 & 6 & Plant hormone signal transduction \\
\hline Solyc01g108087.1 & ABF4 & 0 & 1.87 & 1.96 & 6 & Plant hormone signal transduction \\
\hline Solyc01g108280.3 & SRK2E & 0 & 1.38 & 1.23 & 6 & Plant hormone signal transduction \\
\hline Solyc03g120390.3 & IAA17 & 0 & 1.39 & 1.39 & 6 & Plant hormone signal transduction \\
\hline Solyc03g121060.3 & IAA26 & 0 & 1.18 & 0.9 & 6 & Plant hormone signal transduction \\
\hline Solyc03g121880.3 & $\mathrm{HAB} 1(\mathrm{PP} 2 \mathrm{C})$ & 0 & 1.56 & 1.57 & 6 & Plant hormone signal transduction \\
\hline Solyc04g012160.3 & SAPK2 & 0 & 1.5 & 1.39 & 6 & Plant hormone signal transduction \\
\hline Solyc04g054320.3 & TGA1A & 0 & 0.82 & 1.04 & 6 & Plant hormone signal transduction \\
\hline Solyc04g078840.3 & ABF2 & 0 & 2.69 & 2.51 & 6 & Plant hormone signal transduction \\
\hline Solyc05g014260.3 & ARR11 & 0 & 2.03 & 1.72 & 6 & Plant hormone signal transduction \\
\hline Solyc05g015610.3 & AHK3(CRE1) & 0 & 1.27 & 1 & 6 & Plant hormone signal transduction \\
\hline Solyc05g052980.3 & $\mathrm{PP} 2 \mathrm{CA}$ & 0 & 1.43 & 1.49 & 6 & Plant hormone signal transduction \\
\hline
\end{tabular}


Table 2 Key DEGs that are involved in the resistance response to infection by RKNs and are enriched according to the trend analysis of $25^{\circ} \mathrm{C}$ line (growing at a soil temperature of $25^{\circ} \mathrm{C}$ ) (Continued)

\begin{tabular}{lllllll}
\hline Gene ID & Symbol & CK-log2 (1) & log2(HR0 vs. HR3) & log2(HR0 vs. HR6) & Profile & Pathway \\
\hline Solyc06g061180.1 & PYR1 & $\mathbf{0}$ & $\mathbf{0 . 9 8}$ & $\mathbf{1 . 1 7}$ & 6 & Plant hormone signal transduction \\
Solyc06g072650.1 & SAUR71 & $\mathbf{0}$ & $\mathbf{2 . 0 9}$ & $\mathbf{2 . 1 2}$ & $\mathbf{6}$ & Plant hormone signal transduction \\
Solyc06g074320.3 & TGA21 & $\mathbf{0}$ & $\mathbf{1 . 1 3}$ & $\mathbf{0 . 7}$ & $\mathbf{2}$ & Plant hormone signal transduction \\
Solyc06g076400.3 & At2g29380(PP2C) & $\mathbf{0}$ & $\mathbf{2 . 1 6}$ & $\mathbf{2 . 5 3}$ & $\mathbf{6}$ & Plant hormone signal transduction \\
Solyc07g040990.3 & Os01g0583100(PP2C) & $\mathbf{0}$ & $\mathbf{1 . 3 1}$ & $\mathbf{1 . 3 6}$ & 6 & Plant hormone signal transduction \\
Solyc08g060810.3 & EBF1 & $\mathbf{0}$ & $\mathbf{1 . 2 5}$ & $\mathbf{1 . 1 7}$ & 6 & Plant hormone signal transduction \\
Solyc08g082180.3 & PYL9 & $\mathbf{0}$ & $\mathbf{0 . 9 8}$ & $\mathbf{1 . 2 5}$ & 6 & Plant hormone signal transduction \\
Solyc09g007020.1 & /(PR1) & $\mathbf{0}$ & $\mathbf{4 . 0 3}$ & $\mathbf{4 . 8 3}$ & 6 & Plant hormone signal transduction \\
Solyc10g009290.1 & BHLH14(MYC2) & $\mathbf{0}$ & $\mathbf{2 . 7 8}$ & $\mathbf{2 . 4 3}$ & 6 & Plant hormone signal transduction \\
Solyc10g018340.1 & SAUR36 & $\mathbf{0}$ & $\mathbf{1 . 2 9}$ & $\mathbf{1 . 7}$ & 6 & Plant hormone signal transduction \\
Solyc10g078670.2 & /(TGA) & $\mathbf{0}$ & $\mathbf{1 . 8 1}$ & $\mathbf{1 . 1 3}$ & 6 & Plant hormone signal transduction \\
Solyc12g044870.1 & EIN4(ETR) & $\mathbf{0}$ & $\mathbf{3 . 2}$ & $\mathbf{1 . 7 4}$ & 6 & Plant hormone signal transduction \\
Solyc12g056860.2 & TGA7 & $\mathbf{0}$ & $\mathbf{1 . 2 6}$ & $\mathbf{1 . 1 9}$ & 6 & Plant hormone signal transduction \\
\hline
\end{tabular}

\section{Validation of RNA-seq data via RT-qPCR}

To validate the RNA-seq results, 15 DEGs with different expression patterns were selected for qRT-PCR analysis via gene-specific primers (Additional file 4). All of these candidate genes were screened from the $34{ }^{\circ} \mathrm{C}$ vs. $25^{\circ} \mathrm{C}$ comparison at $3 \mathrm{dpi}$, and there was a strong positive correlation coefficient $\left(R^{2}=0.9404\right)$ between the qRT-PCR results and the RNA-seq data, suggesting that the RNAseq data were reproducible and reliable (Fig. 12).

\section{Discussion}

In recent years, the $M i-3$ gene has attracted increased attention because of its heat-stable characteristics, as this gene remains active when soil temperatures reach $32{ }^{\circ} \mathrm{C}$. In the present study, the results of disease resistance tests demonstrated that accession LA3858 was susceptible to $M$. incognita when the plants were growing at a soil temperature of $34{ }^{\circ} \mathrm{C}$ compared with a normal soil temperature $\left(25^{\circ} \mathrm{C}\right)$. We further elucidated the regulatory networks and models of the $\mathrm{Mi}-3$ gene via RNA-seq and a WGCNA (Figure S3). And RNA-seq was used to verify the transcriptomic profiles of LA3858 in response to $M$. incognita, and the reliability of the RNA-seq data was verified by the significant positive correlation detected between the qRT-PCR data and the RNA-seq data (Additional file 5). GO analysis revealed that most of the DEGs were enriched in the "cell wall", "external encapsulating structure", "cell division" and other key terms at 3 dpi between $34^{\circ} \mathrm{C}$ and $25^{\circ} \mathrm{C}$, which may be related to $\mathrm{GC}$ formation [17]. DEGs were significantly enriched in each of the identified KEGG pathways, which were shown to be associated with plant immunity in a previous study. The initial stage of infection was a key period for RKN penetration and migration in tomato [18]; thus, on the basis of this timing, 3 dpi was selected as the primary stage for analysis.

Table 3 Key DEGs that are involved in the resistance response to infection by RKNs and are enriched according to the trend analysis of $34^{\circ} \mathrm{C}$ line (growing at a soil temperature of $34^{\circ} \mathrm{C}$ )

\begin{tabular}{lllllll}
\hline Gene ID & Symbol & CK-log2 (1) & $\log 2$ (HSO vs. HS3) & log2(HSO vs. HS6) & Profile & Pathway \\
\hline Solyc01g099620.3 & RBOHB & $\mathbf{0}$ & $\mathbf{- 1 . 6 7}$ & $\mathbf{- 0 . 3 5}$ & 2 & Plant-pathogen interaction \\
Solyc02g037540.2 & At4g27220(RPS2) & $\mathbf{0}$ & $\mathbf{- 1 . 1 3}$ & $\mathbf{0 . 1 3}$ & $\mathbf{2}$ & Plant-pathogen interaction \\
Solyc02g072393.1 & At3g47570(FLS2) & $\mathbf{0}$ & $\mathbf{- 1 . 9 8}$ & $\mathbf{- 0 . 6 2}$ & $\mathbf{2}$ & Plant-pathogen interaction \\
Solyc02g072480.3 & GSO1(FLS2) & $\mathbf{0}$ & $\mathbf{- 1 . 4 2}$ & $\mathbf{- 0 . 3 2}$ & $\mathbf{2}$ & Plant-pathogen interaction \\
Solyc05g010670.3 & Hsp83 & $\mathbf{0}$ & $\mathbf{- 1 . 1 6}$ & $\mathbf{- 0 . 3 4}$ & $\mathbf{2}$ & Plant-pathogen interaction \\
Solyc06g066370.3 & WRKY33 & $\mathbf{0}$ & $\mathbf{- 1 . 7 2}$ & $\mathbf{- 0 . 4 2}$ & $\mathbf{2}$ & Plant-pathogen interaction \\
Solyc06g068680.3 & RBOHD & $\mathbf{0}$ & $\mathbf{- 0 . 6 7}$ & $\mathbf{0 . 3 8}$ & $\mathbf{2}$ & Plant-pathogen interaction \\
Solyc07g008620.1 & /(EIX) & $\mathbf{0}$ & $\mathbf{- 1 . 5}$ & $\mathbf{- 0 . 4 4}$ & 2 & Plant-pathogen interaction \\
Solyc11g071750.2 & CML37 & $\mathbf{0}$ & $\mathbf{- 1 0 . 9 1}$ & $\mathbf{- 3 . 8 2}$ & 2 & Plant-pathogen interaction \\
\hline
\end{tabular}




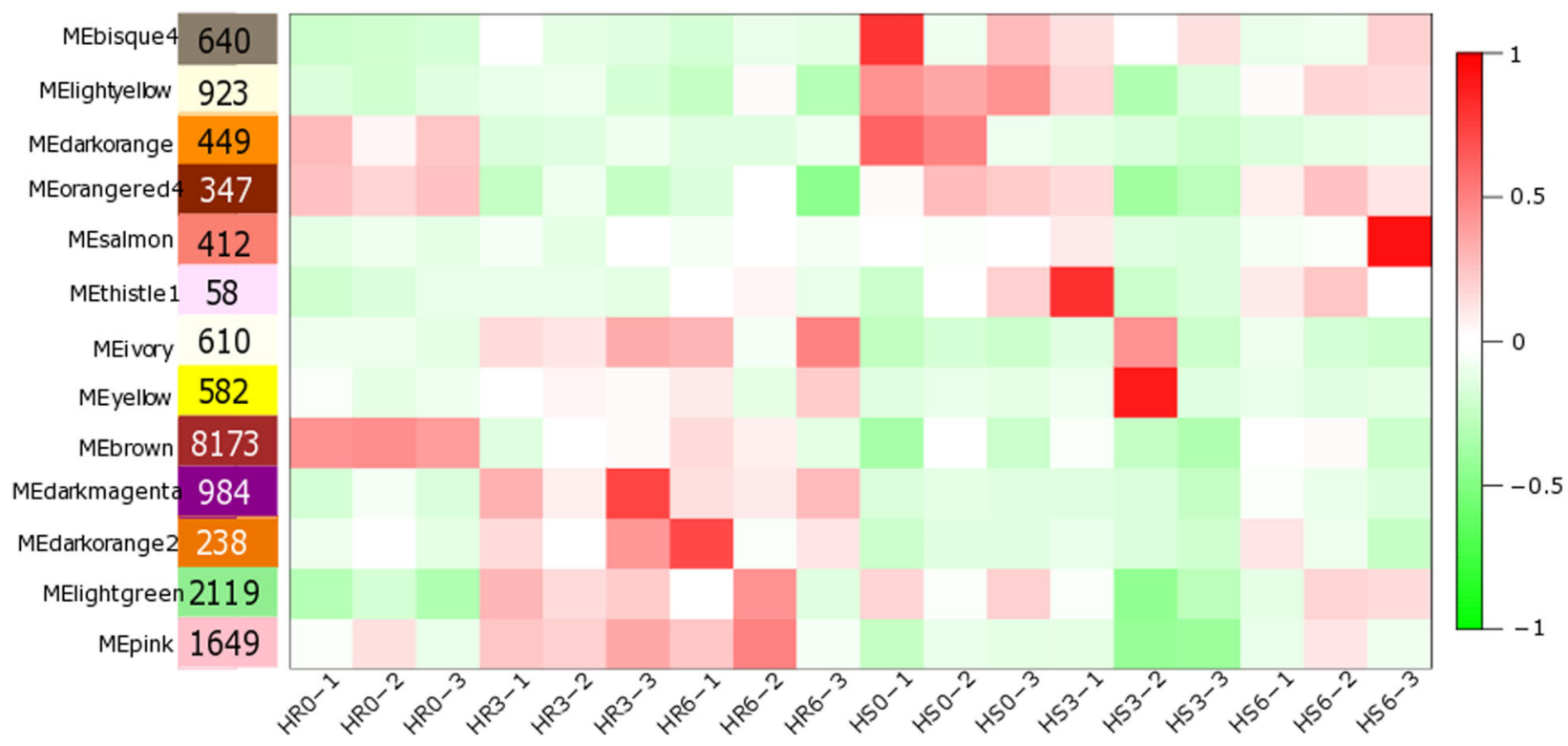

Fig. 8 Expression pattern analysis of plant samples according to WGCNA. The expression pattern of the module genes in each sample is represented by the module eigenvalue. The abscissa represents the sample, and the ordinate represents the module, which is plotted with the module eigenvalues. The red color represents a high expression level, the green color represents a low expression level, and the number of DEGs in each module is shown

\section{The PTI defense system is formed by Mi-3-mediated disease resistance}

The resistance formed in response to external stimuli in plants is referred to as the plant natural immune system and can be divided into two levels, the first of which is called PTI. Plant-surface PRRs specifically recognize the conserved molecular structure of PAMPs of the pathogen, eventually inducing PTI [19]. flg22 is by far the most researched type of PAMP, which is specifically recognized by FLS2 [20]. In this work, LA3858 plants growing at $25^{\circ} \mathrm{C}$ soil temperature were resistant to $M$. incognita, and compared with those in plants growing at a $34{ }^{\circ} \mathrm{C}$ soil temperature, the expression of Solyc02g072480.3-, Solyc04g014650.3- and Solyc06g006020.2-encoded FLS2 was upregulated at $3 \mathrm{dpi}$. And Solyc06g006020.2 were having an increasing trend in $25^{\circ} \mathrm{C}$ line (profile 6) at $3 \mathrm{dpi}$ and $6 \mathrm{dpi}$; however, Solyc02g072480.3 and another DEG (Solyc02g072393.1) also encoding FLS2 tended to decrease in $34^{\circ} \mathrm{C}$ line (profile 2) at both 3 and 6 dpi (Tables 1,2 and 3). This most likely indicated that in plants with $\mathrm{Mi}-3$ at $34^{\circ} \mathrm{C}$ soil temperature, losing resistance was related to the obstruction of developing PTI. After PRRs recognize PAMP molecules, plants can induce rapid defense responses in a short period of time, which can involve activating mitogen-activated protein kinase (MAPK) signaling pathways, increasing ROS levels, and activating SA and JA signaling pathways [21].

\section{Increases in $\mathrm{Ca}^{2+}$ signal channels and ROS in response to $\mathrm{J} 2$ inoculation}

After PTI develops, $\mathrm{Ca}^{2+}$ signal channels are instantly activated by MAPKs, and both CMLs and CDPKs are important components of these channels [22, 23]. The expression of three DEGs encoding CPK2, CPK16 and CML41 was upregulated at $3 \mathrm{dpi}$ in the $34{ }^{\circ} \mathrm{C}$ vs. $25^{\circ} \mathrm{C}$ comparison. Previous research has suggested that CDPKs are closely related to ROS levels during pathogen damages. RBOHs, also known as plant NADPH oxidases, are involved in the production of ROS. $\mathrm{RBOH} \mathrm{N}$ terminal domains contain two EF-hands, which are involved in calcium binding [24]. Via protein phosphorylation, RBOHs are activated to produce ROS [25]. Consistent with this function, in the present study, RBOHs were encoded by 3 DEGs whose expression was upregulated at $25^{\circ} \mathrm{C}$ compared with $34{ }^{\circ} \mathrm{C}$ at $3 \mathrm{dpi}$. Therein, Solyc06g068680.3, which encodes RBOHD, was also significantly enriched $(P \leq 0.05)$ in $25^{\circ} \mathrm{C}$ line according to the results of the trend analysis (profile 6), and its expression was downregulated in $34^{\circ} \mathrm{C}$ line (profile 2) at both 3 and 6 dpi (Tables 1, 2 and 3). It was also found that this DEG is a hub gene in the pink module and that its regulates the production of ROS together with that of Solyc12g005030.2, which encodes another CDPK (Additional file 2). Apparently, RBOHD-dependent ROS production may play a positive role during $M$. incognita 


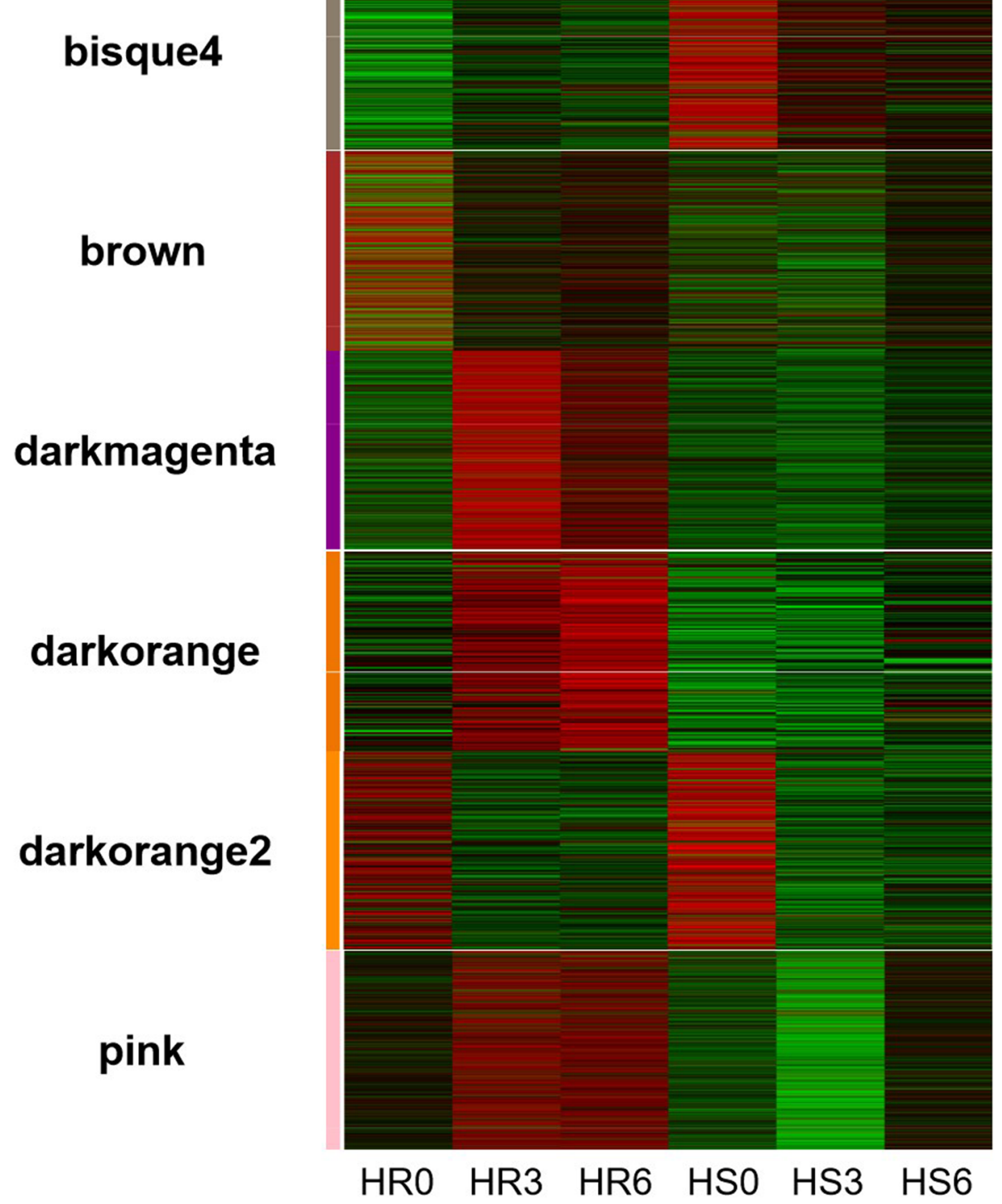

Fig. 9 Heatmap of gene expression patterns for resistance-specific WGCNA modules. The expression pattern of each gene within each module is shown in a heat map. The left column represents the 6 modules, and the 6 vertical columns represent the 0-day, 3-day and 6-day time points from both lines $\left(25^{\circ} \mathrm{C}\right.$ and $34^{\circ} \mathrm{C}$ ). Each column shows the gene expression in the different samples. The genes in the darkorange and pink modules were significantly expressed at 3 and $6 \mathrm{dpi}$ and are involved in the regulation of disease resistance. The red color indicates genes whose expression level increased, and the green color indicates genes whose expression levels decreased

infection. According to a previous study, early production of ROS could be a key biological barrier against disease progression in plant development [26]. In the process of $M i$-3-mediated resistance, we speculate that, owing to the rapid accumulation of ROS, M. incognita at the J2 stage cannot survive the relatively high oxygen concentration in the environment. Furthermore, cell damage and PCD resulting from ROS may be two reasons why nematode feeding sites (NFSs) could not be established, which prevented nutrient extraction and prevented RKNs from forming GCs [3].
Differential expression of WRKY TFs between $34^{\circ} \mathrm{C}$ and $25^{\circ} \mathrm{C}$ soil temperatures

When $\mathrm{Ca}^{2+}$ signal channels are instantaneously activated, in addition to ROS levels, the expression of downstream TFs is also regulated [27]. The results indicated that the expression of many more TFs whose encoding genes were significantly enriched was upregulated at $3 \mathrm{dpi}$. WRKY TFs are extremely important in plant growth and disease resistance and are widely studied in tomato [28]. The expression of six key genes encoding WRKY TFs was significantly upregulated at $25^{\circ} \mathrm{C}$ compared with $34{ }^{\circ} \mathrm{C}$ at 3 


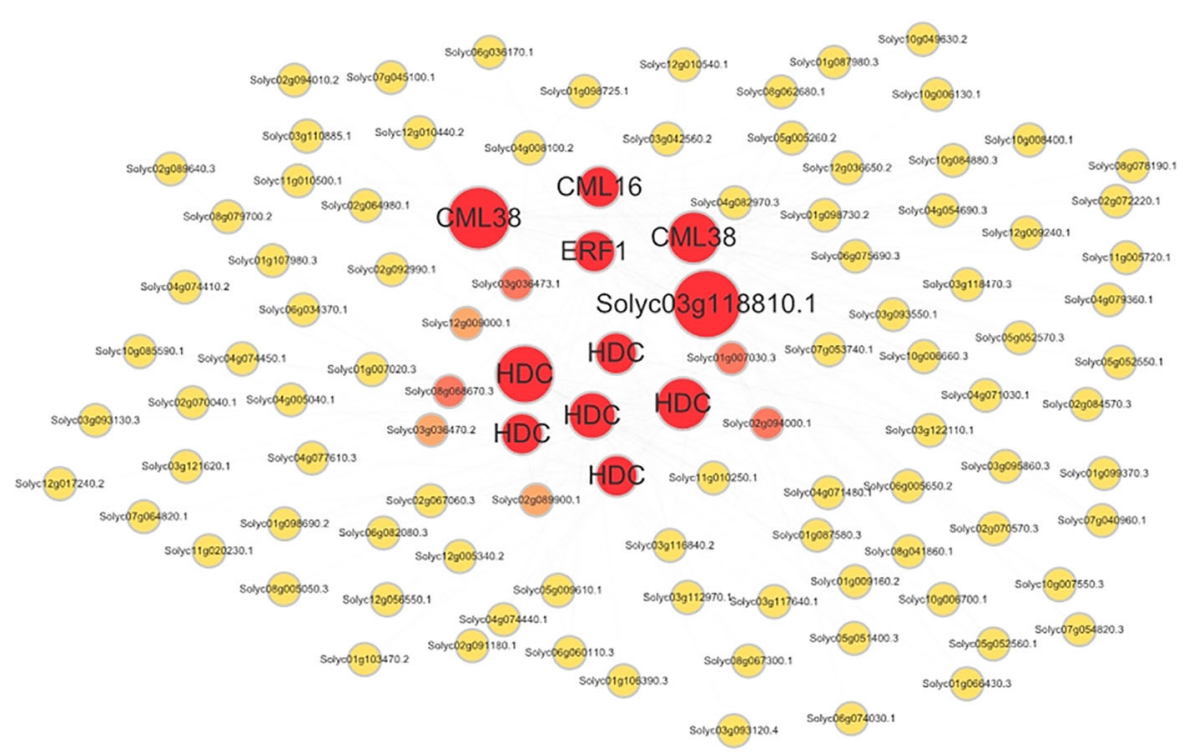

(A)

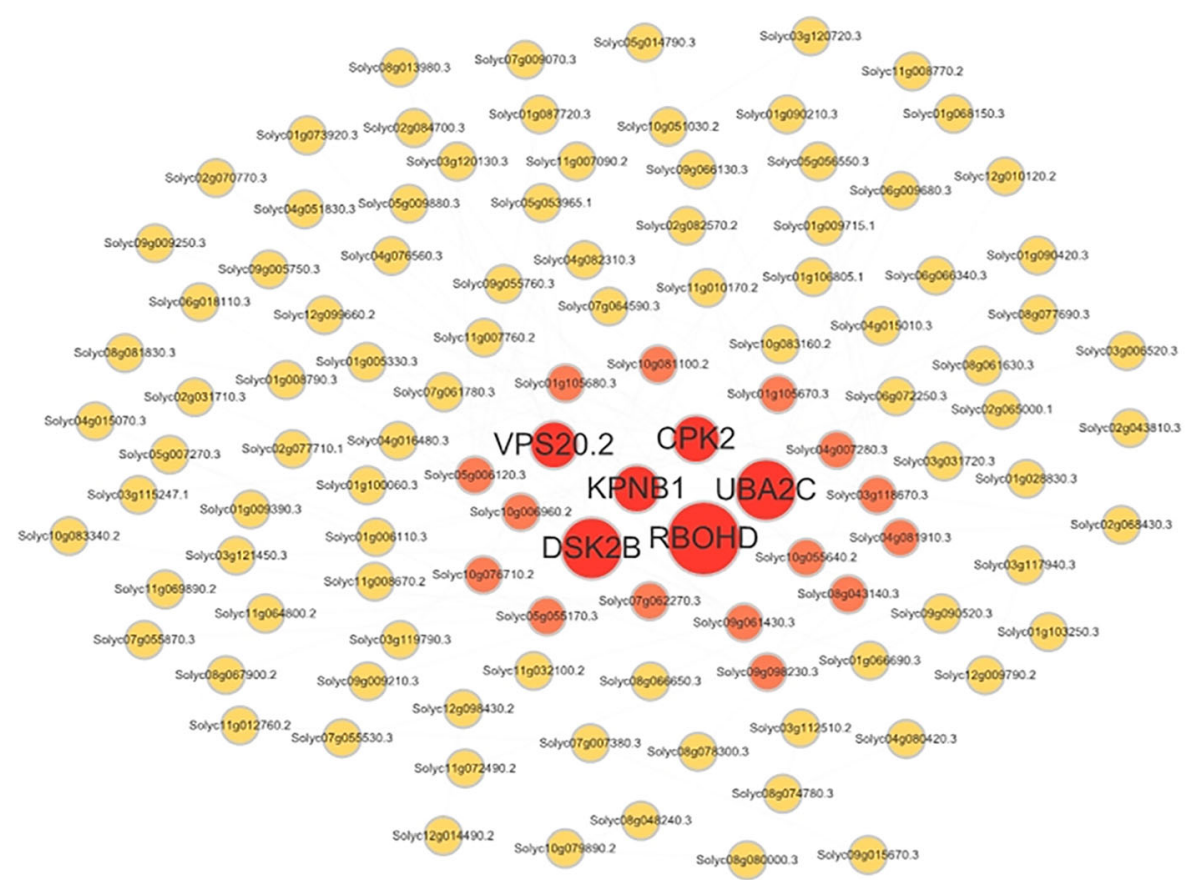

(B)

Fig. 10 Coexpression network of the pink and darkorange modules according to WGCNA. (a) and (b) represent the darkorange and pink modules, respectively, which were filtered from the six modules by WGCNA. The red circles represent hub genes in the darkorange and pink modules, the pathway "plant-pathogen interaction" are significantly enriched

dpi. Among these TF genes, the expression of Solyc04g051540.3, Solyc12g006170.2, Solyc10g009550.3, Solyc08g067340.3, Solyc01g095630.3 and Solyc03g095770.3, which encode WRKY13, 20, 30, 40, 41 and 70, respectively, differed by approximately 5.10-, 2.58-, 9.23-, 4.70-, 3.46- and 4.91-fold (Additional file 3). In addition to WKRY20, which was most likely related to drought tolerance [29], other five WRKYs all might contribute to plants disease defense. In a previous study, WRKY13 was shown to mediate disease resistance to RKNs by activating SA-dependent 


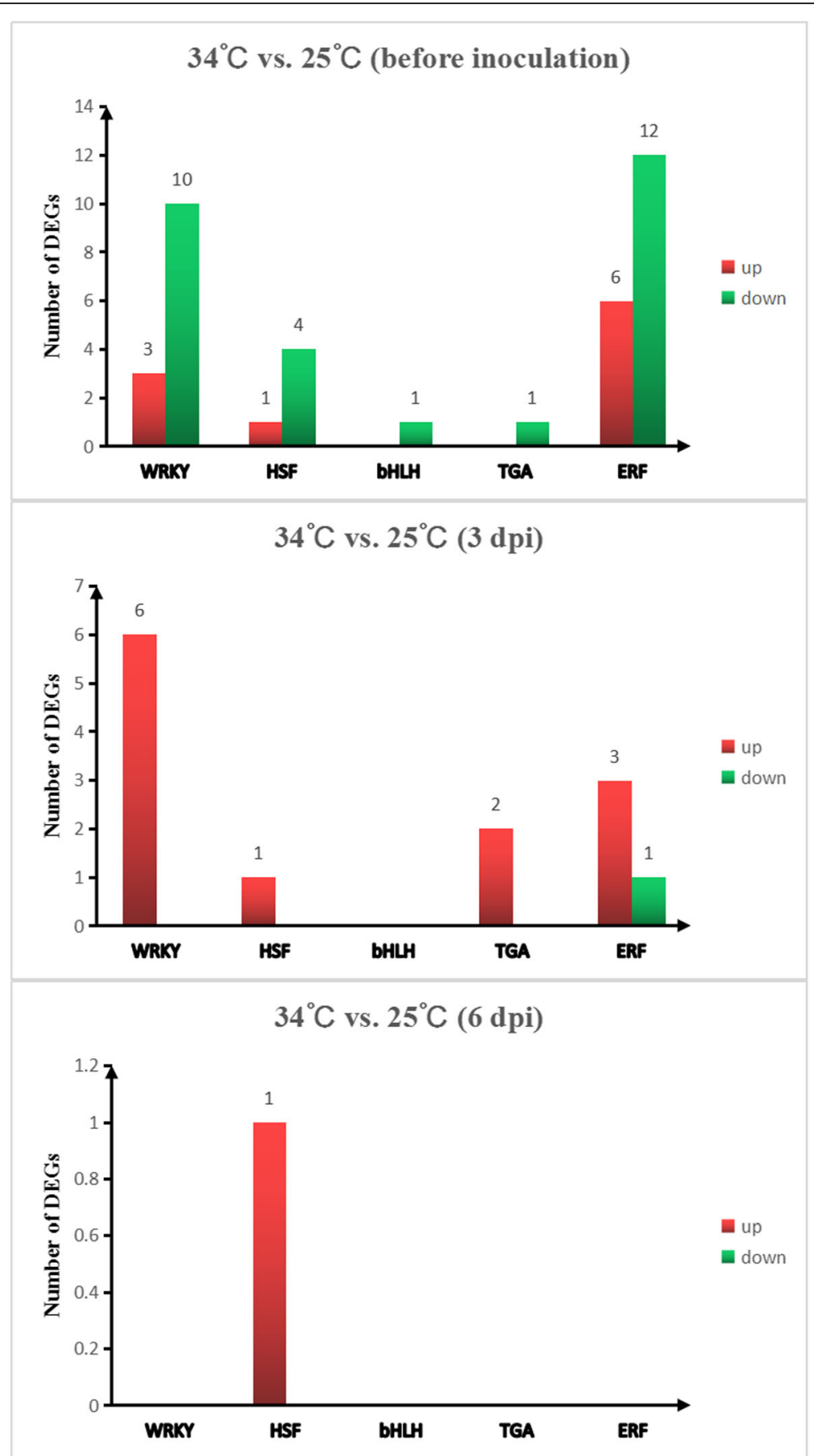

Fig. 11 Number of WRKY, HSF, bHLH, TGA and ERF TFs significantly enriched in the $34^{\circ} \mathrm{C}$ vs. $25^{\circ} \mathrm{C}$ comparison at 0 (before inoculation), 3 and $6 \mathrm{dpi}$

pathways and by suppressing JA-dependent pathways in rice [30]. Overexpression of WRKY3O in rice increased resistance to rice sheath blight fungus by upregulating the expression of the JA synthesis-related genes $L O X$ and AOS2 and a series of pathogenesis-related (PR) genes [31]. The expression of GmWRKY4O was strongly induced in soybean following infection with Phytophthora sojae, and silencing GmWRKY40 was shown to increase susceptibility [32]. WRKY41 is likely to be a key regulator in the cross talk of SA and JA pathways. The overexpression of WRKY41 leads to an increasing of PR5 expression, for enhancing the resistance to Pto wild-type [33]. Other studies have shown that, in tomato, silencing of SlWRKY70 attenuates Mi-1-mediated resistance against RKNs [34]. In short, WRKYs are 


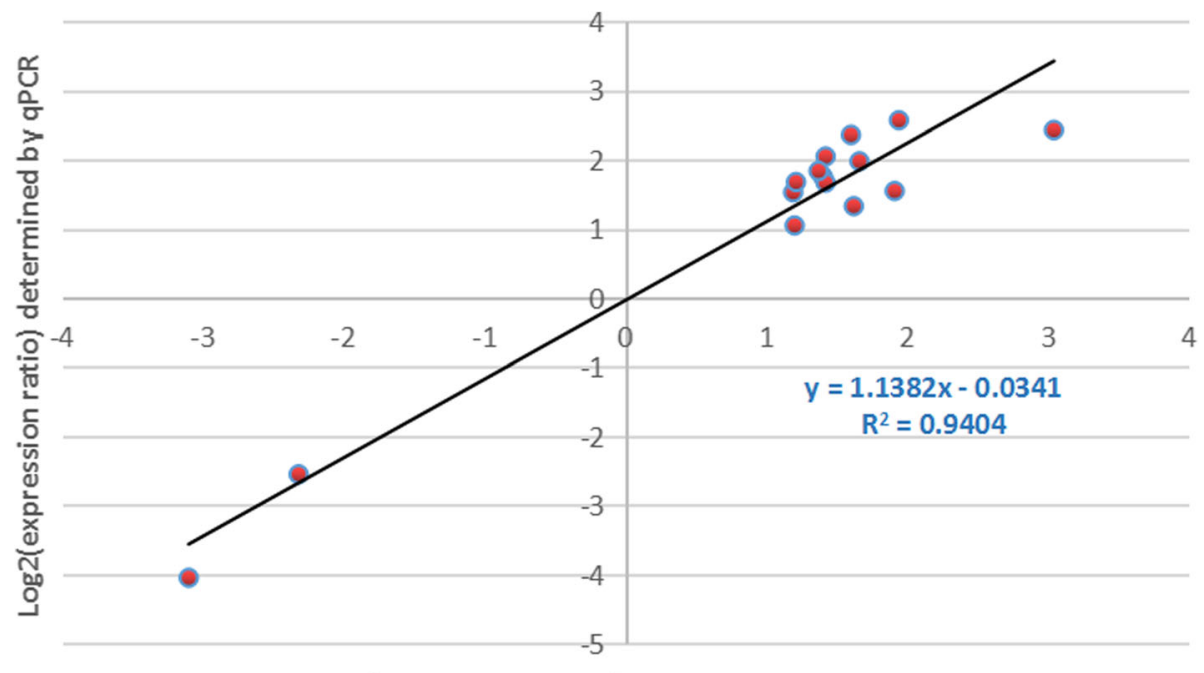

Log2(expression ratio) determined by RNA-seq

Fig. 12 qRT-PCR validation of the RNA-seq results. Validation of gene expression (15 genes) via Pearson correlations ( $r$ values) between FCs (log2 scale) reported for the qRT-PCR results and RNA-seq results

often involved in various defense mechanisms associated with plant growth and stress responses. Despite their involvement in the regulation of expression of some key $P R$ genes and $R$ genes, many WRKYs may also contribute to JA- and SA-defense signaling processes $[35,36]$.

\section{Phytohormone regulation during $M$. incognita infection}

Phytohormones have simple molecular structures and low cellular levels [16]. SA, JA and ET play crucial roles in resistance to biotrophic and necrotrophic pathogens, and TGAs, MYC2 and ERFs are key TFs involved in the biosynthesis of the above three phytohormones [37]. In this research, Solyc10g009290.1 was found to encode MYC2, which, as a member of the basic helix-loop-helix (bHLH) TF family, controls JA-dependent responses and was highly expressed in $25^{\circ} \mathrm{C}$ line (profile 6). 2 and 3 DEGs encoding TGA and ERF TFs, respectively, were highly expressed at $3 \mathrm{dpi}$ between $34^{\circ} \mathrm{C}$ and $25^{\circ} \mathrm{C}$. Moreover, the expression of several DEGs that encoded ethylene receptors (ETRs), EIN3-binding F-box proteins (EBF1/2), and ethylene-insensitive protein 3 (EIN3) was upregulated in $25^{\circ} \mathrm{C}$ line (profile 6), which contributed to the biosynthesis of the ET (Table 2). In addition, Solyc03g093610.1, which encodes the ET-responsive TF (ERF1), was a hub gene in the darkorange module (Additional file 2). Previous reports have shown that obstacles to the synthesis or accumulation of SA result in consistent increases in the number of phenotypes associated with susceptibility to soybean cyst nematode (SCN) [38]. JA can reduce the damage caused by RKNs, and a recent report revealed that, in JA-overexpressing transgenic tomato plants, proteinase inhibitor II (PI-II) translation levels gradually increased with time after inoculation with RKN; this increase was related to the production of JA, which acts at the initial site of infection, inhibiting nematode invasion and propagation [39]. ERF1 integrates defense signals from the ET and JA pathways and induces the expression of downstream defense-related genes [40]. In short, SA and JA defense signaling processes are important components of the first-layer defense mechanism of plants after the development of PTI [38]. According to previous research, both signaling pathways are likely to be involved in Mi-3-mediated resistance to M. incognita.

Roles of induced disease resistance genes related to $\mathrm{Mi}-3$ When a host plant recognizes a pathogen and produces an immune response, the pathogen will produce a substance-an effector-to inhibit the host's recognition. To prevent additional damage, plants directly or indirectly recognize effectors via $R$ proteins, and initiate a rapid and violent hypersensitive response at the infection site, which constitutes the second level of ETI [19]. Most $R$ genes encode proteins that include a unique NBS-LRR domain. Members of the NBS-LRR protein family generally participate in downstream signal transduction during plant-pathogen interactions [41].

Two genes (Solyc08g007250.2 and Solyc04g007090.1) were found to encode the disease RPs RPS2 and RPM1, which attracted our attention because of their significant increase $(P \leq 0.05)$ in expression at $25^{\circ} \mathrm{C}$ compared with $34{ }^{\circ} \mathrm{C}$ at $3 \mathrm{dpi}$. It was suggested that both RPM1 and RPS2 are members of the NBS-LRR protein family. A previous report showed that these two $R$ proteins 
recognize the AvrRpm1 type III effector avirulence protein involved in protecting plants against pathogens [42]. The Solyc04g007090.1 gene encodes RPM1 and exhibited 2.58- and 2.71-FCs in expression levels in $25^{\circ} \mathrm{C}$ line (profile 6) at 3 and $6 \mathrm{dpi}$, respectively; this gene was not obviously enriched in $34{ }^{\circ} \mathrm{C}$ line (profile 2). In addition, the gene Solyc02g037540.2, which encodes another RPS2, showed 2.57- and 2.71-fold increases in $25^{\circ} \mathrm{C}$ line (profile 6) at 3 and $6 \mathrm{dpi}$, respectively. And showed downward trend in $34{ }^{\circ} \mathrm{C}$ line (profile 2). Therefore, RPM1 and RPS2 may be key proteins during infection. Additionally, Solyc09g059430.3 was found to encode RIN4, a negative regulator of basal defense responses, whose expression was upregulated in $25^{\circ} \mathrm{C}$ line (profile 6) along with that of PRS2 and RPM1 (Tables 1, 2 and 3). The biological functions of these two $\mathrm{R}$ proteins are associated with RIN4 [43]. RIN4 physically interacts with RPM1 and indirectly interacts with RPS2. Moreover, the RPM1 and RPS2 proteins work together to maintain RIN4 expression levels during pathogen infection [44]. However, the biological mechanisms of these three proteins, which are regulated by $M i-3$, in response to RKNs require further study.

HSPs may play a positive role against nematode infection In most cases, disease resistance mediated by both RPS2 and RPM1 is associated with RAR1, SGT1 and HSPs. RAR1 interacts with the N-terminal half of HSP90, which contains an ATPase domain, and HSP90 specifically interacts with SGT1. In Arabidopsis, the interaction of these three proteins regulates the stability and function of RPM1, which is an HSP-client protein [45]. In this study, the expression of Solyc05g010670.3 and Solyc06g036290.3, each of which encodes an HSP90 (Hsp83 and HSP83A), was upregulated at $25^{\circ} \mathrm{C}$ compared with $34{ }^{\circ} \mathrm{C}$ at $3 \mathrm{dpi}$; therein, the expression of Solyc05g010670.3 obviously tended to decrease in $34{ }^{\circ} \mathrm{C}$ line (profile 2), and Solyc06g036290.3 had a significant increasing trend in $25^{\circ} \mathrm{C}$ line (profile 6) at 3 and $6 \mathrm{dpi}$ (Tables 1, 2 and 3). Additionally, another 2 DEGs were found to encode HSP90 (HSP83A, HSC80), and the expression both tended to increase in $25^{\circ} \mathrm{C}$ line (profile 6). According to a previous study, genes that encode certain HSPs activated by HSFs perceive biotic stress signals via $\mathrm{Ca}^{2+}$ channels, which are highly expressed at the soybean Rhg1 locus and are involved in resistance to SCN [46]. In addition, silencing of tomato HSP90 and SGT1 led to a reduction in Mi-1 protein levels, which reduced resistance to $M$. incognita [47], demonstrating that HSP90 contributes to the resistance process in plants and that DEGs encoding HSPs in our study might have a positive effect during infection of LA3858 by nematodes. Moreover, the production of HSP can also used as a standard for detecting levels of ROS in plants [48, 49].

\section{Conclusion}

In summary, this is the first report on the resistance and susceptibility of $\mathrm{Mi}-3$ at the transcriptional level under different soil temperatures. A soil temperature of $32{ }^{\circ} \mathrm{C}$ is likely to be limiting for $\mathrm{Mi}-3$ activity, which is consistent with the previous research. When the soil temperature was less than $32{ }^{\circ} \mathrm{C}$, after $M$. incognita infected the roots, a rapid response (PTI) occurred, and downstream signal transduction was most likely triggered through $\mathrm{Ca}^{2+}$ channels via MAPKs and other signaling pathway components. Key defense-related TFs were subsequently triggered, such as HSFs, TGAs, ERFs, bHLHs and WRKYs, which activated disease RPs and downstream defense pathways, such as the SA, JA and ET pathways. Notably, HSPs likely associated with R proteins such as RPM1 and RPS2 in the development of ETI during infection. Last, the formation of a hypersensitive response in the roots was likely induced by ROS, resulting in cell damage and $\mathrm{PCD}$. These actions prevented the establishment of root NFSs and might constitute a key mechanism for specific resistance to $M$. incognita.

\section{Methods}

\section{Plant growth conditions and nematode assays}

Seeds of S. peruvianum accession LA3858 were obtained from the Institute of Vegetables and Flowers, Chinese Academy of Agricultural Sciences, and seeds of the susceptible breeding line Moneymaker were obtained from the Northeast Agricultural University Tomato Research Institute. At $20-25$ days after the seeds were sown in plots, when the seedlings reached a height of $12-15 \mathrm{~cm}$ (the second-leaf stage), they were transplanted into 10$\mathrm{cm}$-diameter plastic pots that each contained $50 \%$ turf soil and 50\% roseite. The plants were maintained at a $24 \pm 2{ }^{\circ} \mathrm{C}$ temperature, at $60 \%$ relative humidity and under a 14-h light/10-h dark photoperiod [50]. The $M$. incognita strain was obtained from the Institute of Vegetables and Flowers, Chinese Academy of Agricultural Sciences. We obtained infected roots and stripped the egg masses, which were cleaned with $1 \% \mathrm{NaOCl}$, after which the eggs were hatched in distilled water to obtain J2-stage individuals for inoculation [51].

\section{Heat treatment for phenotypic identification and transcriptomic analysis}

Approximately 60 plants of accession LA3858 and Moneymaker were grown at different soil temperatures $\left(25^{\circ} \mathrm{C}, 32^{\circ} \mathrm{C}\right.$ and $\left.34^{\circ} \mathrm{C}\right)$ for five days before inoculation. Afterward, 8 plants of both lines in each treatment were randomly picked for gall and egg mass counting 45-50 days after inoculation with 2000 J2-stage $M$. incognita nematodes per plant. For transcriptomic analysis of accession LA3858, high-temperature assays were 
performed in a greenhouse in which the soil temperature was greater than $32{ }^{\circ} \mathrm{C}\left(34^{\circ} \mathrm{C}\right)$ five days before inoculation. In the other group, the plants were grown at normal temperature $\left(25^{\circ} \mathrm{C}\right)$. Afterward, the roots of plants from the two groups were collected at 0 days (before inoculation) and at 3 and 6 days post-inoculation (dpi) with $2000 \mathrm{~J} 2$-stage $M$. incognita nematodes per plant [52]. At each time point, the roots of three replicates were collected. For each biological replicate, inoculated tissue was collected from 3 random plants, and the tissue samples were pooled together to obtain sufficient root tissue materials for RNA-seq and qRT-PCR verification. All root tissue samples were stored in liquid nitrogen and then transferred to $-80^{\circ} \mathrm{C}$ conditions.

\section{Disease score on root systems}

The roots were removed from the soil, washed for several minutes, cleaned with a $\mathrm{NaOCl}$ solution, soaked in distilled water for $15 \mathrm{~min}$, and then dyed with acid fuchsin. Finally, the galls and egg masses were counted under a microscope to assess the resistance. The root gall index (percentage of roots with galls) and the resistance index (rated according to the root gall index) were the standards used for evaluating disease resistance, and each was divided into 6 levels as follows: 0 - no galls, $1-$ $1-10 \%$ of roots with galls, $2-10-20 \%, 3-20-50 \%, 4-50-$ $80 \%$, and $5-80-100 \%$ for the former and immune (I), highly resistant (HR), resistant (R), moderately resistant (MR), susceptible (S), and highly susceptible (HS) for the latter [53].

\section{mRNA library construction and sequencing}

In total, eighteen independent mRNA libraries from the roots of LA3858 plants in 2 treatments $\left(25^{\circ} \mathrm{C}\right.$ soil temperature and $34{ }^{\circ} \mathrm{C}$ soil temperature) and at three time points ( 0 days, 3 days, 6 days) with three biological replicates per treatment were sequenced [54]. After the total RNA was isolated via TRIzol ${ }^{\text {Tst }}$ reagent (No: 15596026, Thermo Fisher Scientific), oligo (dT) beads were used to enrich the eukaryotic mRNA, while prokaryotic mRNA was enriched by the removal of rRNA with a Ribo-Zero ${ }^{\text {Tn }}$ Magnetic Kit (Epicentre). The enriched mRNA was then fragmented into short fragments by fragmentation buffer and reverse transcribed into cDNA with random primers. Second-strand cDNA was synthesized with DNA polymerase I, RNase H, dNTPs and buffer. The cDNA fragments were then purified with a QiaQuick PCR Extraction Kit, end repaired, polyadenylated and then ligated to Illumina sequencing adapters. The appropriate sizes of the ligation products were selected via agarose gel electrophoresis, amplified by PCR, and sequenced by an Illumina HiSeq 2500 instrument by Gene Denovo Biotechnology Co. (Guangzhou, China). All the raw read data have been deposited into the NCBI Sequence Read Archive database (PRJNA494774).

\section{Analysis of DEGs}

To identify DEGs across the 18 samples, the edgeR package (http://www.rproject.org/) was used. We considered genes significantly differentially expressed when their $\log _{2} \mid$ fold change $(\mathrm{FC}) \mid$ was $>1$ and their false discovery rate (FDR) was $<0.05$ in a particular comparison $[55,56]$. Gene expression pattern analysis was then used to cluster genes with similar expression patterns for multiple samples (at least 3 at a specific time point, space, or treatment dose). To examine the expression pattern of the DEGs, the expression data for each sample (in the order of treatment) were normalized to 0 , $\log 2(\mathrm{v} 1 / \mathrm{v} 0)$ transformed, and $\log 2(\mathrm{v} 2 / \mathrm{v} 0)$ transformed, after which they were clustered via Short Time-series Expression Miner (STEM) software [57]. The clustered profiles with $P$-values $\leq 0.05$ were considered significant. The DEGs in the profiles were then subjected to Gene Ontology (GO) functional analysis and KEGG pathway enrichment analysis. In this article, trend analysis was performed by clustering gene expression patterns of the characteristics of multiple continuous samples (at least 3 ). The gene sets that met certain biological characteristics were then selected from the clustering results. And trend analysis was together used to discuss DEGs that are in the same line and are associated with pairwise comparisons.

\section{Weighted gene coexpression network analysis (WGCNA)} WGCNA is a systems biology method for describing correlation patterns among genes across multiple samples. Genes that express similar patterns can be clustered and analyzed for associations between modules and specific traits or phenotypes. In this study, coexpression networks were constructed via the WGCNA (v1.47) package in $\mathrm{R}$ [58]. After the low-quality samples and samples that had an unstable effect on the results (genes that were not expressed in more than half of the samples and samples in which more than half of the genes were not expressed) were removed, the gene expression values were subjected to a WGCNA to construct coexpression modules via the automatic network construction function blockwiseModules with the default settings, with the exceptions that the power was 6, the TOMType was unsigned, the mergeCutHeight was 0.8 , and the minModuleSize was $50[59,60]$.

To identify biologically significant modules, eigengenes were used to calculate the correlation coefficients with samples or sample traits. The intramodular connectivity (function softConnectivity) of each gene was calculated, and genes with a high connectivity tended to be hub genes (q. weighted $<0.01$ as a cutoff) [61], which may act as key factors that regulate a large subset of genes to perform biological functions together. The networks were subsequently visualized by Cytoscape 3.3.0. 


\section{qRT-PCR and validation of RNA-seq results}

qRT-PCR was performed to validate the accuracy of the RNA-seq results. First-strand cDNA was synthesized via a RevertAid First Strand cDNA Synthesis Kit (K1621) from Thermo Scientific. Each sample included three biological replicates. We used the NCBI BLAST program to design the primers used for the unigenes. Relative quantitative data were calculated according to the $\Delta \Delta \mathrm{CT}$ method: normalization $(\triangle \mathrm{CT}=\mathrm{CT} \quad$ (sample) $-\mathrm{CT}$ $(\mathrm{GAPDH})) ; \Delta \Delta \mathrm{CT}=\Delta \mathrm{CT}$ (sample A) $-\Delta \mathrm{CT}$ (sample B); relative quantification $=2^{-\Delta \Delta C \mathrm{~T}}$ [62].

\section{Supplementary information}

Supplementary information accompanies this paper at https://doi.org/10. 1186/s12864-020-6654-5

Additional file 1 Disease resistance statistics of LA3858 and

Moneymaker infected with $M$. incognita after treatment with different soil temperatures.

Additional file 2. List of hub genes filtered from darkorange and pink modules by WGCNA.

Additional file 3. List of transcription factors significantly enriched in the $34^{\circ} \mathrm{C}$ vs. $25^{\circ} \mathrm{C}$ comparison at 0 (before inoculation), 3 and $6 \mathrm{dpi}$.

Additional file 4. List of qRT-PCR primers used in this study.

Additional file 5. Verification of the correlation results between the RNA-seq and qRT-PCR data

Additional file 6: Figure S1 Level $2 \mathrm{GO}$ terms identified for DEGs in $34^{\circ} \mathrm{C}$ vs. $25^{\circ} \mathrm{C}$ comparison at 0 (before inoculation), 3 and $6 \mathrm{dpi}$.

Additional file 7: Figure S2 Top 20 significantly enriched pathways in the darkorange and pink modules according to WGCNA.

Additional file 8: Figure S3 Description of all the analyses performed in this work.

\section{Abbreviations}

CDPK: Calcium-dependent protein kinase; DEGs: Differentially expressed genes; dpi: Post-inoculation; ET: Ethylene; ETI: Effector-triggered immunity; FLS2: LRR receptor-like serine/threonine-protein kinases; GCs: Giant cells; HSFs: Heat shock transcription factors; HSPs: Heat shock proteins; JA: Jasmonic acid; NADPH: Nicotinamide adenine dinucleotide phosphate; NBS-LRR: Nucleotide-binding site-leucine-rich repeat; NFS: Nematode feeding sites; PAMPs: Pathogen-associated molecular patterns; PCD: Programmed cell death; PTI: Pathogen-triggered immunity; RBOHs: Respiratory burst oxidases; RKNs: Root-knot nematodes; ROS: Reactive oxygen species; SA: Salicylic acid; SCN: Soybean cyst nematode

\section{Acknowledgments}

We thank the Gene Denovo at Guangzhou for its assistance in related bioinformatics analysis.

\section{Authors' contributions \\ Conceived and designed the experiments: CD, JL, XX. Performed the experiments: CD, JJ, HZ, DZ. Participated in the field trials: CD, JJ, ZZ. Analyzed the data: CD, TZ, HY. Contributed reagents/materials/analysis tools: $C D, J J, Z Z, J L$. Wrote the manuscript: CD, TZ, HY. All authors have read and approved the final version of the manuscript.}

\section{Funding}

This work was supported by the Major Research Plan (2016YFD0101703) and National Outstanding Youth Foundation of China (Grant No. 31501777).

\section{Availability of data and materials}

We have deposited our data in Sequence Read Archive (SRA) (http://www. ncbi.nlm.nih.gov/sra/), the accession number for our submissions are: PRJNA494774.
Ethics approval and consent to participate

Not applicable.

\section{Consent for publication}

Not applicable.

\section{Competing interests}

The authors declare that they have no competing interests.

Received: 13 March 2019 Accepted: 4 March 2020

Published online: 23 March 2020

\section{References}

1. Trudgill DL. Origins of root-knot nematodes (Meloidogyne spp., Nematoda) in relation to their cultural control [J]. Phytoparasitica. 1995;23(3):191-4.

2. Schaff JE, Nielsen DM, Smith CP, et al. Comprehensive transcriptome profiling in tomato reveals a role for glycosyltransferase in Mi-mediated nematode resistance [J]. Plant Physiol. 2007;144(2):1079-92.

3. Das S, Ehlers JD, Close TJ, et al. Transcriptional profiling of root-knot nematode induced feeding sites in cowpea (Vigna unguiculata L. Walp.) using a soybean genome array [J]. BMC Genomics. 2010;11(1):480.

4. Meldau S, Ullman-Zeunert L, Govind G, et al. MAPK-dependent JA and SA signalling in Nicotiana attenuata affects plant growth and fitness during competition with conspecifics [J]. BMC Plant Biol. 2012;12(1):213.

5. Kochetov AV, Glagoleva AY, Strygina KV, et al. Differential expression of NBSLRR-encoding genes in the root transcriptomes of two Solanum phureja genotypes with contrasting resistance to Globodera rostochiensis [J]. BMC Plant Biol. 2017;17(2):251.

6. Sacco MA, Koropacka K, Grenier E, et al. The cyst nematode SPRYSEC protein RBP-1 elicits Gpa2-and RanGAP2-dependent plant cell death [J]. PLoS Pathog. 2009;5(8): e1000564.

7. Seah S, Yaghoobi J, Rossi M, et al. The nematode-resistance gene, Mi-1, is associated with an inverted chromosomal segment in susceptible compared to resistant tomato [J]. Theor Appl Genet. 2004;108(8):1635-42.

8. Devran Z, Göknur A, Mesci L. Development of molecular markers for the Mi1 gene in tomato using the KASP genotyping assay [J]. Hortic Environ Biotechnol. 2016:57(2):156-60.

9. Reddy YS, Sellaperumal C, Prasanna HC, et al. Screening of tomato genotypes against root-knot nematode and validation of Mi 1 gene linked markers [J]. Proc Natl Acad Sci India Sect B. 2018;88(1):65-72.

10. Jablonska B, Ammiraju JSS, Bhattarai KK, et al. The Mi-9 gene from Solanum arcanum conferring heat-stable resistance to root-knot nematodes is a homolog of Mi-1[J]. Plant Physiol. 2007;143(2):1044-54.

11. Yaghoobi J, Yates JL, Williamson VM. Fine mapping of the nematode resistance gene Mi-3 in Solanum peruvianum and construction of a $S$. lycopersicum DNA contig spanning the locus [J]. Mol Gen Genomics. 2005; 274(1):60-9.

12. Yaghoobi J, Kaloshian I, Wen $Y$, et al. Mapping a new nematode resistance locus in Lycopersicon peruvianum [J]. Theor Appl Genet. 1995;91(3):457-64.

13. Maboreke HR, Feldhahn L, Bönn M, et al. Transcriptome analysis in oak uncovers a strong impact of endogenous rhythmic growth on the interaction with plantparasitic nematodes [J]. BMC Genomics. 2016;17(1):627.

14. Bali S, Vining K, Gleason C, et al. Transcriptome profiling of resistance response to Meloidogyne chitwoodi introgressed from wild species Solanum bulbocastanum into cultivated potato [J]. BMC Genomics. 2019;20(1):907.

15. Melillo MT, Leonetti $\mathrm{P}$, Leone $\mathrm{A}$, et al. ROS and NO production in compatible and incompatible tomato-Meloidogyne incognita interactions [J]. Eur J Plant Pathol. 2011;130(4):489-502.

16. Depuydt S, Hardtke CS. Hormone signalling crosstalk in plant growth regulation [J]. Curr Biol. 2011;21(9):R365-73.

17. Wang $X$, Cheng $C$, Zhang $K$, et al. Comparative transcriptomics reveals suppressed expression of genes related to auxin and the cell cycle contributes to the resistance of cucumber against Meloidogyne incognita [J]. BMC Genomics. 2018;19(1):583.

18. Shukla N, Yadav R, Kaur P, et al. Transcriptome analysis of root-knot nematode (Meloidogyne incognita)-infected tomato (Solanum lycopersicum) roots reveals complex gene expression profiles and metabolic networks of both host and nematode during susceptible and resistance responses [J]. Mol Plant Pathol. 2018;19(3):615-33. 
19. Hong $C Y$, Zheng $J L$, Chen TY, et al. PFLP-intensified disease resistance against bacterial soft rot through the MAPK pathway in PAMP-triggered immunity [J]. Phytopathology. 2018;108(12):1467-74.

20. Smith JM, Heese A. Rapid bioassay to measure early reactive oxygen species production in Arabidopsis leave tissue in response to living Pseudomonas syringae [J]. Plant Methods. 2014;10(1):6.

21. Dong S, Yin W, Kong G, et al. Phytophthora sojae avirulence effector Avr3b is a secreted NADH and ADP-ribose pyrophosphorylase that modulates plant immunity [J]. PLoS Pathog. 2011;7(11): e1002353.

22. Zhang K, Han YT, Zhao FL, et al. Genome-wide identification and expression analysis of the CDPK gene family in grape, Vitis spp [J]. BMC Plant Biol. 2015; 15(1):164.

23. Davies LJ, Brown CR, Elling AA. Calcium is involved in the $R_{M C l}(b / b)^{-}$ mediated hypersensitive response against Meloidogyne chitwoodi in potato [J]. Plant Cell Rep. 2015;34(1):167-77.

24. Liu Y, He C. Regulation of plant reactive oxygen species (ROS) in stress responses: learning from AtRBOHD [J]. Plant Cell Rep. 2016;35(5):995-1007.

25. Zhang JZ, Zhao K, Ai XY, et al. Involvements of PCD and changes in gene expression profile during self-pruning of spring shoots in sweet orange (Citrus sinensis)[J]. BMC Genomics. 2014;15(1):892.

26. Li R, Rashotte AM, Singh NK, et al. Integrated signaling networks in plant responses to sedentary endoparasitic nematodes: a perspective [J]. Plant Cell Rep. 2015;34(1):5-22

27. Wang JP, Xu YP, Munyampundu JP, et al. Calcium-dependent protein kinase (CDPK) and CDPK-related kinase (CRK) gene families in tomato: genomewide identification and functional analyses in disease resistance [J]. Mol Gen Genomics. 2016;291(2):661-76.

28. Huang S, Gao Y, Liu J, et al. Genome-wide analysis of WRKY transcription factors in Solanum lycopersicum [J]. Mol Gen Genomics. 2012;287(6):495-513.

29. Ning W, Zhai H, Yu J, et al. Overexpression of Glycine soja WRKY2O enhances drought tolerance and improves plant yields under drought stress in transgenic soybean [J]. Mol Breed. 2017;37(2):19.

30. Nguyễn PV, Bellafiore $S$, Petitot AS, et al. Meloidogyne incognita-rice (Oryza sativa) interaction: a new model system to study plant-root-knot nematode interactions in monocotyledons [J]. Rice. 2014;7(1):1-13.

31. Peng $X$, Hu $Y$, Tang $X$, et al. Constitutive expression of rice WRKY30 gene increases the endogenous jasmonic acid accumulation, $P R$ gene expression and resistance to fungal pathogens in rice [J]. Planta. 2012;236(5):1485-98.

32. Cui $X$, Yan Q, Gan S, et al. GmWRKY40, a member of the WRKY transcription factor genes identified from Glycine max L., enhanced the resistance to Phytophthora sojae [J]. BMC Plant Biol. 2019;19(1):1-15.

33. Higashi $K$, Ishiga $Y$, Inagaki $Y$, et al. Modulation of defense signal transduction by flagellin-induced WRKY41 transcription factor in Arabidopsis thaliana [J]. Mol Gen Genomics. 2008;279(3):303-12.

34. Atamian HS, Eulgem T, Kaloshian I. SIWRKY70 is required for Mi-1-mediated resistance to aphids and nematodes in tomato [J]. Planta. 2012;235(2):299_ 309.

35. Rushton PJ, Somssich IE, Ringler P, et al. WRKY transcription factors [J]. Trends Plant Sci. 2010;15(5):247-58.

36. Tao Z, Liu H, Qiu D, et al. A pair of allelic WRKY genes play opposite roles in rice-bacteria interactions [J]. Plant Physiol. 2009;151(2):936-48.

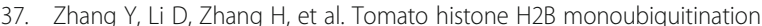
enzymes SIHUB1 and SIHUB2 contribute to disease resistance against Botrytis cinerea through modulating the balance between SA-and JA/ETmediated signaling pathways [J]. BMC Plant Biol. 2015;15(1):252.

38. Matthews BF, Beard $\mathrm{H}$, Brewer $\mathrm{E}$, et al. Arabidopsis genes, AtNPR1, AtTGA2 and AtPR-5, confer partial resistance to soybean cyst nematode (Heterodera glycines) when overexpressed in transgenic soybean roots [J]. BMC Plant Biol. 2014;14(1):96.

39. Ma KW, Ma W. Phytohormone pathways as targets of pathogens to facilitate infection [J]. Plant Mol Biol. 2016;91(6):713-25.

40. Cao FY, DeFalco TA, Moeder W, et al. Arabidopsis Ethylene Response Factor 8 (ERF8) has dual functions in ABA signaling and immunity [J]. BMC Plant Biol. 2018;18(1):211.

41. Kang YJ, Kim KH, Shim S, et al. Genome-wide mapping of NBS-LRR genes and their association with disease resistance in soybean [J]. BMC Plant Biol. 2012;12(1):139

42. Geng $X$, Shen M, Kim JH, et al. The Pseudomonas syringae type III effectors AvrRpm1 and AvrRpt2 promote virulence dependent on the F-box protein COl1[J]. Plant Cell Rep. 2016;35(4):921-32.
43. Axtell MJ, Staskawicz BJ. Initiation of RPS2-specified disease resistance in Arabidopsis is coupled to the AvrRpt2-directed elimination of RIN4[J]. Cell. 2003;112(3):369-77.

44. Mackey D, Belkhadir Y, Alonso JM, et al. Arabidopsis RIN4 is a target of the type III virulence effector AvrRpt2 and modulates RPS2-mediated resistance [J]. Cell. 2003;112(3):379-89.

45. Takahashi A, Casais C, Ichimura K, et al. HSP90 interacts with RAR1 and SGT1 and is essential for RPS2-mediated disease resistance in Arabidopsis [J]. Proc Natl Acad Sci. 2003;100(20):11777-82.

46. Kandoth PK, Ithal N, Recknor J, et al. The soybean Rhg1 locus for resistance to the soybean cyst nematode Heterodera glycines regulates the expression of a large number of stress-and defense-related genes in degenerating feeding cells [J]. Plant Physiol. 2011;155(4):1960-75.

47. Van Ooijen G, Lukasik E, Van Den Burg HA, et al. The small heat shock protein 20 RSI2 interacts with and is required for stability and function of tomato resistance protein I-2[J]. Plant J. 2010;63(4):563-72.

48. Hubert DA, Tornero P, Belkhadir Y, et al. Cytosolic HSP90 associates with and modulates the Arabidopsis RPM1 disease resistance protein [J]. EMBO J. 2003;22(21):5679-89.

49. Barcala M, García A, Cubas P, et al. Distinct heat-shock element arrangements that mediate the heat shock, but not the late-embryogenesis induction of small heat-shock proteins, correlate with promoter activation in root-knot nematode feeding cells [J]. Plant Mol Biol. 2008;66(1-2):151-64.

50. Bagnaresi P, Sala T, Irdani T, et al. Solanum torvum responses to the rootknot nematode Meloidogyne incognita [J]. BMC Genomics. 2013;14(1):540.

51. Hussey RS. A comparison of methods of collecting inocula of Meloidogyne spp., including a new technique [J]. Plant Dis Rep. 1973;57:1025-8.

52. Kong LA, Wu DQ, Huang WK, et al. Large-scale identification of wheat genes resistant to cereal cyst nematode Heterodera avenae using comparative transcriptomic analysis [J]. BMC Genomics. 2015;16(1):801.

53. Taylor AL, Sasser JN. Biology, identification and control of root-knot nematodes (Meloidogyne spp.)[J]. Raleigh: North Carolina State University Graphics; 1978.

54. Schroeder A, Mueller O, Stocker S, et al. The RIN: an RNA integrity number for assigning integrity values to RNA measurements [J]. BMC Mol Biol. 2006; $7(1): 3$.

55. Zhou R, Yu X, Zhao T, et al. Physiological analysis and transcriptome sequencing reveal the effects of combined cold and drought on tomato leaf [J]. BMC Plant Biol. 2019;19(1):377.

56. Zhao T, Liu W, Zhao Z, et al. Transcriptome profiling reveals the response process of tomato carrying Cf-19 and Cladosporium fulvum interaction [J]. BMC Plant Biol. 2019;19(1):1-12.

57. Ernst J, Bar-Joseph Z. STEM: a tool for the analysis of short time series gene expression data [J]. BMC Bioinformatics. 2006;7(1):191.

58. Langfelder $P$, Horvath S. WGCNA: an R package for weighted correlation network analysis [J]. BMC Bioinformatics. 2008;9(1):559.

59. Botía JA, Vandrovcova J, Forabosco $P$, et al. An additional k-means clustering step improves the biological features of WGCNA gene coexpression networks [J]. BMC Syst Biol. 2017;11(1):47.

60. Moschen S, Higgins J, Di Rienzo JA, et al. Network and biosignature analysis for the integration of transcriptomic and metabolomic data to characterize leaf senescence process in sunflower [J]. BMC Bioinformatics. 2016;17(5):174.

61. Xu P, Yang J, Liu J, et al. Identification of glioblastoma gene prognosis modules based on weighted gene co-expression network analysis [J]. BMC Med Genet. 2018;11(1):1-12

62. Köppel $R$, Bucher TB. Duplex real-time PCR for the determination of wasabi (Eutrema wasabi) contents in horseradish (Armoracia rusticana) products applying the $\Delta \Delta \mathrm{ct}-\mathrm{method}[\mathrm{J}]$. Eur Food Res Technol. 2016;242(7):1111-5.

\section{Publisher's Note}

Springer Nature remains neutral with regard to jurisdictional claims in published maps and institutional affiliations. 